\title{
1997 Fall Meeting Reflects Popularity and Breadth of MRS Meetings
}

The 1997 MRS Fall Meeting was held in Boston from December 1-5, 1997 jointly at the Boston Marriott Hotel/Copley Place, the Westin Hotel/Copley Place, and the Sheraton Boston Hotel. The Meeting was chaired by Harry A. Atwater (California Institute of Technology), Dean W. Face (DuPont), Peter F. Green (University of Texas-Austin) and A. Lindsay Greer (Cambridge University).

Over 4,500 attendees participated. The meeting included 41 topical symposia, as well as tutorials and the exhibit. A total of 3,816 papers were presented giving an attendee to paper ratio of $1: 2$, with a $9 \%$ abstract rejection rate. Poster sessions were scheduled at all three hotels for the first time, with several symposia holding their own poster presentations.

\section{Symposium X, Award Talks Update Nonspecialists in Various Materials Research Topics}

At the Awards ceremony, held on Wednesday, Von Hippel Award recipient Gabor A. Somorjai (University of California-Berkeley), Turnbull Lectureship Award recipient Merton C. Flemings (Massachusetts Institute of Technology), and MRS Medalist Shuji Nakamura (Nichia Chemical Industries Ltd., Japan) were honored. In addition, graduate student awards were presented at the ceremony, and members of the MRS new building task force-consisting of Carl Thompson, Alan Taub, Merrilea Mayo, Charles Duke, and John Ballance-were recognized for their contribution.

The award ceremony was followed by Somorjai's talk on surface science, "From Surface Materials to Surface Technologies." He started with several important surface-related technological achievements including catalytic converters, zeolite and molecular carbon sieves used for air separation, diamond-coated drills, the Xerox electrophotographic process, and transistors in Intel chips. These are all related to the developments of molecular surface science. He detailed what he considered to be the four important surface properties: relaxation/ reconstruction, adsorption, coadsorption, and coverage dependence of restructuring. He concluded by identifying seven major future directions for surface science and technology, particularly emphasizing biocompatible surfaces that have the potential for significant applica- tions in human implants.

In his talk entitled "Solidification Science and Engineering Practice," presented as part of Symposium B on Phase Transformations and Systems Driven Far From Equilibrium, Flemings discussed basic dendritic structures and the Scheil equation, and various facets of solidification including directional solidification (for turbine blades), in situ composites, rapid solidification processing, and production of $\mathrm{Al}-\mathrm{Zr}$ abrasives. He finished the lecture with general comments about the value of mathematical modeling for understanding solidification, which is greatly facilitated by the rapid increase in computing power. He paid a tribute to David Turnbull, who was present at the talk, stressing that educators like him are greatly needed today. Flemings is one of Turnbull's former students.

Jacques Pankove, who invented the GaN LED in the 1970s while at RCA Laboratories, introduced Nakamura who presented his MRS Medalist talk to a standing-room-only audience as part of Symposium X on Frontiers of Materials Research and Symposium D on Nitride Semiconductors. In his talk entitled "IIINitride Lasers and Optoelectronic De-

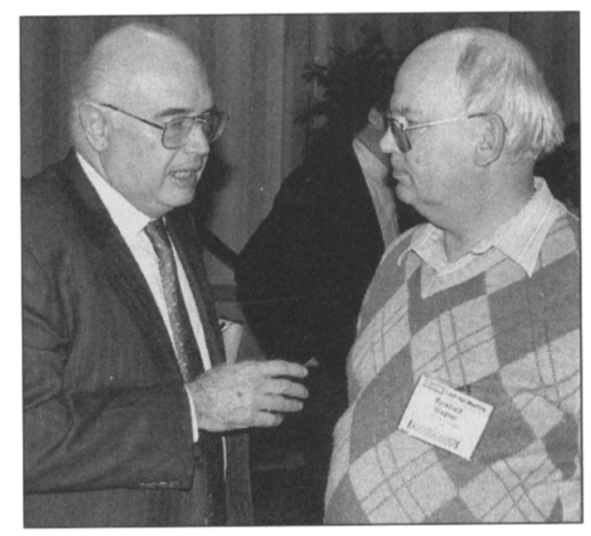

Gabor A. Somoriai of UC-Berkeley (left) follows up his Von Hippel Award talk with informal discussions with meeting attendees at the 1997 MRS Fall Meeting in Boston. During his presentation,

"From Surface Materials to Surface Technologies," Somorjai detailed what he considers to be the four important surface properties: relaxation/reconstruction, adsorption, coadsorption, and coverage dependence of restructuring. vices," Nakamura ran through the development of III-nitrides, dealing first with LEDs and then with nitride lasers. At the end of the talk he demonstrated the laser by shining it on specific phosphor-coated papers of different colors. He also demonstrated the LEDs, including a pen with the blue LED embedded in a transparent case.

At Symposium D, Nakamura announced 10,000 hours of extrapolated $\mathrm{cw}$ blue laser operation at room temperature. Epitaxial lateral overgrowth (ELOG), the technique responsible for Nakamura's recent developments, was covered in several talks. Other than Nichia, six other groups (Toshiba, Cree, Fujitsu, UC-Santa Barbara, Xerox, and Sony) were successful in demonstrating laser operation in nitride semiconductors and all six groups presented their results. The symposium was dedicated to Jacques Pankove.

Look for publication of the three award talks in a future issue of MRS Bulletin.

Other Symposium $X$ talks covered switchable mirrors, photoresist materials, biological ceramics, genetically-engineered materials, and electron-conducting redox hydrogels. Peter Duine (Philips Research Laboratories, Eindhoven, Netherlands) showcased a development of great scientific as well as practical interest in his talk, "Switchable Mirrors from Metal Hydrides." Using Gd-Mg hydrides, and by removing or reintroducing hydrogen, the material could be transformed from a mirror to a nearly transparent material and vice versa. Duine showed a video of the actual working mirror. While the system demonstrated the applications, it is cumbersome for practical use, with connections needed for pumping hydrogen. A solid-state version of the mirror is now under development and one version with a liquid electrolyte has been demonstrated successfully. Numerous practical applications are possible for this technology, including displays, privacy windows, and lights that change luminosity.

Grant Wilson (University of Texas) gave his Symposium $X$ talk on "Advances in Resist Materials." Lithography techniques, which involve patterning a thin layer of polymeric material to define the placement of structures for integrated circuits and other devices, are being pushed to their limits. Feature sizes have reached $0.5 \mu \mathrm{m}$ dimensions and are moving to 250-nm widths. One method of 
achieving still smaller features is through use of shorter wavelength light. However, resists may be opaque to these short wavelengths, requiring development of new resists. And even then, achieving transparency is not enough. Resists need to resist etching or easily dissolve away, based on the chemical changes caused by the light exposure and subsequent chemical processing. The material also benefits from increased light sensitivity, so that weak light sources are effective.

An acid-catalyzed process causing polymer breakdown to happen at lower temperatures can amplify the transition of the resist film from insoluble to soluble. This process has produced structures useful for building semiconductor devices at doses 300 times lower than those required to image standard resists. This chemistry is used in standard processors (e.g., the Pentium $\Pi$ processor) using a wavelength of $240 \mathrm{~nm}$.

Going to shorter wavelengths-such as $193 \mathrm{~nm}$ light-challenges the notion that aromatic structures (e.g., benzene rings) are needed to resist etching. These conjugated structures strongly absorb this wavelength of light, but it has been discovered that the $\mathrm{C}$ to $\mathrm{H}$ ratio, not the conjugated structure, is needed to slow the etch rate, with glassy carbon giving the slowest etch rate. IBM and Toshiba added end groups with a high $\mathrm{C}$-to-H ratio to a methylmethacrylate (Plexiglas) backbone using copolymerization and achieved line widths of $0.15 \mu \mathrm{m}$. However, creating resists with the proper balance of image quality and etch resistance has led to very complicated polymers, plus the methylmethacrylate backbone itself has poor etching resistance.

The next step was to simplify the structure by putting etch-resistant structures into the backbone polymer itself. Norbor-

\section{ACRONYM KEY}

AFM: atomic force microscopy

AFRL: U.S. Air Force Research Laboratory

ANL: Argonne National Laboratory

APXS: alpha proton $x$-ray spectrometer

ARO: Army Research Office

ASU: Arizona State University

BST: barium strontium titanate

CIESE: Center for Improved Engineering

and Science Education

CMR: colossal magnetoresistance

CMU: Carnegie Mellon University

CT: computed tomography

cw: continuous wave

DARPA: Defense Advanced Research Projects Agency

DOE: Department of Energy

DRA: Defence Research Agency (UK)

DRAM: dynamic random-access memory

ELOG: epitaxial lateral overgrowth

ENDOR: electron-nuclear double resonance

FED: field emission display

FGM: functionally graded materials

GM: General Motors

HP: Hewlett-Packard Company

HTS: high-temperature superconductor

HVOF: high-velocity oxy-fuel

IBAD: ion-beam-assisted deposition

IC: integrated circuit

INPE-LAS: Instituto Nacional de Pesquisas

Espaciais-Laboratario Associado de Sensores e Materiais

ir: infrared

ISTEC: International Superconductivity

Technology Center

JFET: junction field-effect transistor

JPL: Jet Propulsion Laboratory

KTH: Kungl. Tekniska Hogskolan (Sweden)

LANL: Los Alamos National Laboratory

LED: light-emitting diode

LEEM: low-energy electron microscopy

LLNL: Lawrence Livermore National Laboratory

MBE: molecular beam epitaxy nene answered this call. It can be made inexpensively and a rich array of polymers can be built on it using free-radical polymerization, addition polymerization, or ring-opening polymerization. Properties such as thermal stability, low-dielectric constant, optical transparency, and good etch rates can be achieved via these methods. Using 193-nm wavelength light, line and space widths to $0.088 \mu \mathrm{m}$ has been achieve by Nippon Electric Company.

Beyond $193 \mathrm{~nm}$, extreme ultraviolet lithography printer technology is being investigated. Here, at $110 \mathrm{~nm}$ wavelength, everything is opaque and new chemistry once again is needed.

In his talk on "Biological Ceramics or All You Wanted to Know about Shells," A.H. Heuer (Case Western Reserve University) spoke about various aspects of the materials science of hard tissues including the avian egg shell, sea urchin spine, magnetotactic bacteria, clam shell, and conch shell. He discussed mechanical properties of the conch shell. The conch shell microarchitecture was used to perform finite element simulation of laminated composites. The talk reinforced biomimetics, the concept of using biological structures to design new materials. Heuer reiterated that laminated brittle structures may deserve more study.

David Tirrell of the University of Massachusetts, Amherst, gave a Symposium $X$ talk on Genetically Engineered Materials. Coventional polymers have a range of chain lengths and atomic weights, and actually represent mixtures consisting of the various chain lengths. Genetic engineering offers a route to the synthesis of new polymers with fixed lengths. According to Tirrell, the technique consists of obtaining a DNA sequence of amino acids as a monomer, and replacing part of a naturally occurring protein obtained from a cell (such as E. Coli) with the monomer units. The recombinant protein is then placed back in the cell and allowed to grow, from where the polymer can be eventually obtained. Twenty different naturally occurring amino acids can be used for building proteins. In addition, artificial amino acids can also be used as monomer units. Tirrell mentioned three major classes of applications for these polymers. The first is polymer crystal design since lamellar structure, thickness, and surface properties can be tailored depending on the chain length. In addition, analogs of amino acids can be used to tailor structure and properties. The second application suggested was as liquid crystals with unusual properties where the layer spacing can be controlled by tailoring the chain length. The third application suggested by Tirrell was mole- 
cular recognition processes, wherein proteins undergo triggered processes under specific conditions. One example given was the formation of a gel in a solution containing the polymers when the $\mathrm{pH}$ of the solution attains a certain value. In summary, Tirrell suggested that these new artificial proteins represent a new class of macromolecules with a covalent molecular architecture, and comprise a new area of polymer materials science.

The Symposium X talk on "ElectronConducting Redox Hydrogels and Their Applications in Biosensors" by Adam Heller (University of Texas-Austin) described the materials science aspects of subcutaneous microsensors that could be implanted in people. Heller described one application in treating diabetes in which his group implanted a microsensor in a chimpanzee in order to monitor blood glucose levels while simultaneously drawing blood samples and measuring the glucose levels. As Heller described it, the microsensor consists of an electronconducting biocompatible polymer immobilized in a hydrogel which is essentially a three-dimensional matrix. One end is in contact with the enzyme (glucose oxidase) where exchange of electrons can occur, while the other end is in contact with an electrode. Electron transport is made possible by the sweeping movement of chains of the polymer via a redox mechanism. The electron flow can be calibrated against glucose concentration levels. The microsensor measurements correlated well with the actual blood glucose levels. The diameter of the active area of the device was twice that of a human hair, hence is not felt by the patient when implanted. It is possible to design a system that can provide an alarm when glucose levels are too low or too high, apart from continuous monitoring of glucose levels. Various other similar applications of such microsensors can also be envisaged.

\section{Technical Sessions Provide Latest Research}

Symposium J on Electrical, Optical and Magnetic Properties of Organic SolidState Materials was the largest component of a cluster of symposia ( $\mathrm{J}-\mathrm{O}$ ) on soft condensed matter incorporating polymers and biomaterials. The development of OLEDs was one of the widely covered highlights of this field. In addition, nanostructure control is an important consideration for OLEDs, and represented an important part of this symposium.

Symposium $\mathrm{K}$ was the first MRS symposium on materials science of the cell, indicating the trend toward increased

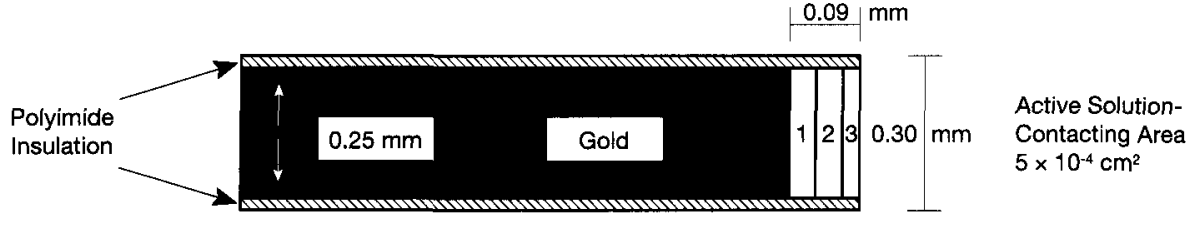

A cross-section of the subcutaneous microsensor described by Adam Heller of the University of Texas-Austin in his Symposium X talk on Electron Conducting Redox Hydrogels. Such microsensors could be implanted in humans to monitor glucose levels in diabetics. The sensing layer 1 is covered by a dynamic range expanding layer 2 and a biocompatible layer 3. The overall diameter is $0.3 \mathrm{~mm}$

interest in biological and biomolecular materials. Highlights included a report on the mechanics of the rotary motor that drives the flagella of $E$. Coli bacteria representing a natural working example of nanotechnology, the display of the nanoscale architecture of biominerals deposited by abalone and diatoms, a report on the use of patterned and functionalized surfaces for liver tissue engineering, and a demonstration of direct measurements of protein unfolding using the AFM tip. Other highlights included a report on the direct measurement of sequence-dependent interaction between two complementary DNA strands by prying apart the DNA double helix with a glass micropipette, and a presentation on a new approach to DNA sequencing by measuring the ionic conductance of a membrane channel protein while a single DNA strand is pulled through by an electric field.

The fifth in a series of biennial symposia on complex fluids-liquids such as amphiphilic phases, gels, and liquid crystals that contain self-assembled structures of length scales intermediate between the molecular and the macroscopic-Symposium L presented recent trends toward using the basic concepts of complex fluids to study biomaterials, as in the joint session with Symposium $\mathrm{K}$ on adsorption and interaction of proteins with membranes.

Symposium $M$ covered advances in polymer matrix composites with emphasis on structure-property analysis at the microscopic level. The various papers covered issues concerning synthesis, processing, interphase/interface, nanostructured composites, fractal theory, percolation, fracture durability, adhesion, toughness, characterization, sensing, and structureproperty relationships.

Polymers in Orthopedics, Symposium $O$, covered a rapidly expanding field within biomaterials science and engineering. Both degradable polymers such as polylactic acid polymers, polyglycolic acid polymers, and polycaprolactone, as well as nondegradable polymers such as polyethylene and polymethylmethacrylate are under study. The various applications under consideration include regeneration of musculoskeletal soft tissues, various orthopedic applications such as development of biodegradable flexible matrix and biodegradable putty for bone repair, carriers of antibiotics and growth factors for controlled localized release, and bone defect fillers.

The advantages of modeling and simulation for the development of new materials were discussed in Symposia P-S. Symposium $P$ demonstrated that quantum mechanical techniques could be used in the development of semiconductor, optical, and magnetic materials where the performance of the material was controlled by a single property determined at a specific length and energy scale. Advances in modeling metallic materials, particularly at the mesoscale, were also demonstrated.

Symposium $\mathrm{R}$ brought together researchers working on various aspects of TB theory, a conceptual framework for a physical understanding of the structure of materials, and its applications to materials science. Progress was reported on the formal front such as first principles TB methodology. The development of linearscaling methods appears to have increased the popularity of the TB method. The application of TB theory to the calculation of materials properties represented a major segment of the symposium. Some of the applications discussed included interaction of light with matter; prediction of atomic, electronic structure, and magnetic properties of disordered metallic alloys; and the physics of semiconductors, liquid alloys, alloy surfaces, and magnetic multilayers.

Complex oxide materials, including superconductors, ferroelectric materials, magnetic materials, and synthesis and processing, were covered in Symposia $\mathrm{T}-\mathrm{W}$. Clearly from papers presented in Symposium T, superconductors are making inroads in "real-world" applications. The status of HTS commercialization 
efforts in Japan, Europe, and the United States was presented in a special session. Major ongoing projects are happening in cables, transformers, magnets, SMES, fault current limiters, motors, and current leads. Also, while HTS wire is good at present, it was reported that reliability and cost are still limiting factors.

Symposium U covered recent advances in ferroelectric thin films. In particular, high-density DRAMs and ferroelectric nonvolatile memories were the focus. BST is currently the most popular material for DRAMs. PZT and the layered perovskite family based on SBT are receiving the most attention for nonvolatile memory applications.

Chemical aspects of electronics ceramics processing was the topic of Symposium $W$, which conducted a tutorial on MOCVD. In the session on diamond, $\mathrm{R}$. Roy (PSU) presented late-breaking news on the use of the three-laser process to alter the structure of a number of materials with significant increase in performance. A panel discussion concluded the symposium, covering topics such as drivers for new materials/technologies, smart materials, and "top down" versus "bottom up" synthesis of materials.

Symposium E represents the first symposium held at an MRS meeting on Power Semiconductor Materials and Devices, among a cluster of symposia devoted to the area of semiconductors (D-I). Power electronics boundaries continued to be pushed by innovative $\mathrm{Si}$ device designs and the use of wide bandgap materials for devices operational at higher voltages and temperatures than the present. Si will clearly continue to dominate the field. It was also evident that hybrid $\mathrm{GaN} / \mathrm{SiC}$ devices will play a major role because of thermal management requirements, while diamond continues to have problems due to difficulty in $n$-type doping.

Infrared applications of semiconductors makes up a broad interdisciplinary field of research as demonstrated in the papers presented in Symposium F. Major highlights included reports on progress in 3-13 $\mu \mathrm{m}$ quantum cascade lasers, improved II-VI detectors with possible near-room temperature and multispectral operation, and novel negative luminescent devices.

Silicon-based optoelectronic devices hold considerable promise as evidenced by the papers presented in Symposium $\mathrm{H}$. Impact excitation of Er ions in Si junctions or e-h recombination in Er-doped microcavities were shown to provide efficient and possibly modulable light emission in the near-infrared. Synthesis of iron

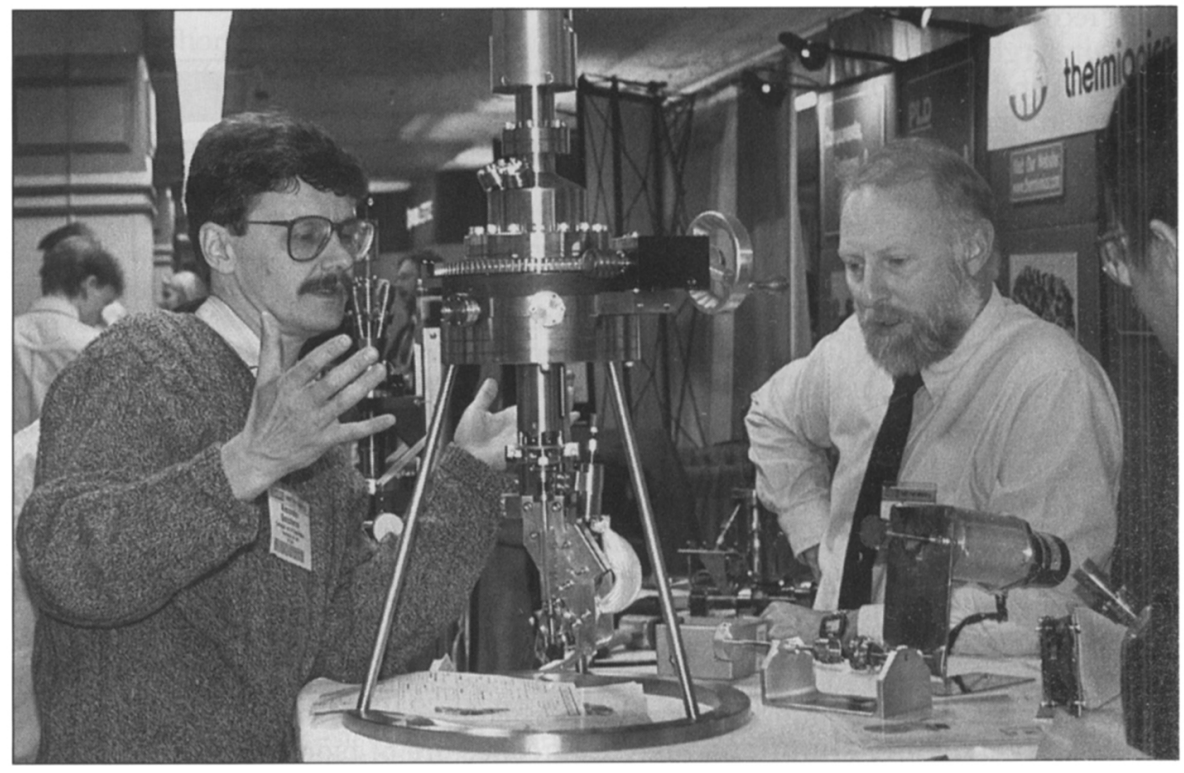

The exhibit opened at 11:30 a.m. Tuesday and continued through Thursday. This was the largest exhibit held at an MRS Meeting with booths filling up every nook and cranny among the three hotels.

disilicide in Si also showed promise in the near-infrared range. Also, efficient integrated modulators using $\mathrm{BaTiO}_{3}$ films and optically pumped amplifiers using Er-doped $\mathrm{Al}_{2} \mathrm{O}_{3}$ apparently hold considerable promise for Si-compatible optoelectronics.

Semiconductors for room-temperature radiation detector applications were covered in Symposium I. Major work in this field is based on cadmium zinc telluride grown by the high pressure Bridgeman method. Cadmium telluride, silicon, and mercuric iodide are also materials of interest. Optimization of device performance was the subject of several papers. Imaging systems, in particular for medical applications, drive commercial interest in this field, and papers were presented based on cadmium zinc telluride, silicon, or silicon coupled with higher atomic number materials such as lead iodide.

The issue of characterization was covered in Symposium HH on holography and IJ on NDE of materials in aging systems. Highlights included talks on characterization of electrically active interfaces and boundaries in electroceramics, imaging the potential distribution in ferroelectric thin films, determination of morphologies of nanostructured materials such as carbon onions and gold nanoparticles, and imaging of polymer microstructures by utilizing the phase-sensitivity of the electron wave to create contrast. Also the economic importance of NDE and its applica- tions in diverse fields such as characterization of cement in civil structures, characterization of aerospace structures, and measurement of radiation embrittlement in nuclear reactor pressure vessels were covered. New NDE techniques discussed included pulsed eddy current crack detection and AFM. An interesting session on MEMS technology included talks on new NDE capabilities such as a digital MEMSbased strain gauge for structural health monitoring and a MEMS device to generate and receive ultrasound.

The areas of thin films and nanostructures were represented in various symposia. Symposium A continued the strong tradition of thin-film research-related symposia at MRS Meetings. The synthesis of thin films of high crystalline perfection is an important area of research as suggested by several papers presented. In addition, polycrystalline texture was the subject of several papers including the effects of film stress, anisotropy of elastic constants, and energetic deposition. Insights on the nanometer-scale physics of crystal surfaces were also revealed using real-time studies of surface dynamics using LEEM and syn chrotron radiation.

Symposium $\mathrm{C}$ on self-organized nanostructures followed a somewhat unusual format. The selection process was rigorous with only $1 / 3$ submitted abstracts accepted. All 24 presentations were of $30-$ minutes duration with the remaining 70 or so papers presented in poster sessions. 
The presentations covered various areas including chemical synthesis of nanocrystals wherein remarkable size uniformity was observed, metal-insulator transition in metal quantum dot films, characterization of electronic properties strained InAs islands grown on GaAs, and doping of nanoclusters with rare-earth atoms.

Carbon and related amorphous-tonanocrystalline thin films are increasingly under consideration for electronic, opti$\mathrm{cal}$, and tribological applications as indicated by the papers presented in symposium AA. The ability of the materials to emit electrons at low temperatures in low electric fields raises the possibility of using them as cold cathodes in flat-panel technology. B.F. Coll (Motorola) described a new $100 \%$ graphitic "nanocoralline" thin-film structure producing $>10^{-6}$ emission sites per $\mathrm{cm}^{2}$ with low operating voltages, which is sufficient for current display requirements.

Symposium FF covered the use of surface-controlled nanoscale materials for high added value applications. Highlights included a talk on surface-controlled nanospheres as blood persistent drug carriers. The study involved using a PLA-PEG (polyethylene glycol) copolymer coating on protein-loaded nanospheres. The human albumin release rate was then measured for different molecular lengths of the polymer coating. A paper on functional DNA/ nanoparticle-based materials described the use of biological macromolecules, DNA in this case, to direct formation of materials at the nanoscopic level. The use of DNA has several advantages, such as automated preparation, molecular recognition, properties, and length scale larger than conventional organic molecules. In one study DNA strands were used to interconnect gold nanoparticles (13-nm diameter). Two different particle sizes were also used to form a duplex structure. Several potential applications of such structures include colorimetric nanoparticle detection.

A significant fraction of papers in Symposium $Y$ on materials for electrochemical energy storage and conversion were based on lithium batteries, a rapidly growing area of interest. In addition, papers were presented on lithium ion rechargeable battery anode materials, carbon anode materials, new colloidal deposition techniques, and sol-gel techniques.

Several advances have been made recently in catalysis, making up the focus of Symposium Z. Papers were presented on the use of STM and STS to study phys$i c a l$ and electronic properties of metal. clusters supported on metal oxides. New ideas described and discussed in this symposium included activating catalyst

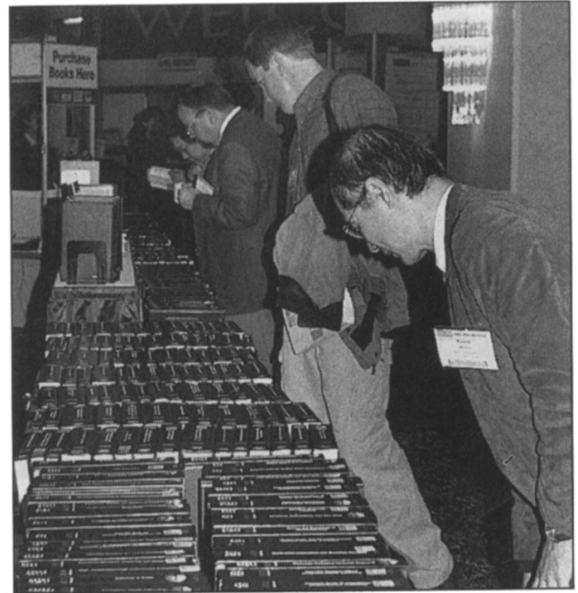

Attendees at the 1997 MRS Fall Meeting browse through the proceedings volumes for sale in the Boston Marriott/Copley Place.

surfaces by manipulation of electronic properties of substrates, the use of oxide catalysts with well-defined structural properties, and the use of structurally tailored and electrically conductive graphite nanofiber and fullerene-based supports.

Symposium GG marked the first time an MRS symposium was devoted to functionally graded materials. Modeling and processing formed the focus of several papers with a stress on structure-property characterization using well-established methods. Several new materials systems were also discussed.

The fundamentals of defects created by energetic particle beams interacting with solid materials was covered in Symposium $\mathrm{KK}$, carrying on the tradition of MRS symposia dealing with beam-solid interactions. Several papers discussed very high energy implantation effects in materials, wherein electronic stopping becomes an important factor even in metals and semiconductors. Several papers also reported progress on the creation of nanoclusters using ion beams in a range of host materials.

The continued importance of cement as a construction material base was highlighted in Symposium MM on cementitious composites. The symposium papers covered new uses of cement-based composites particularly in nontraditional applications, rehabilitation of deteriorating structures, and the use of waste and by-products in cement and concrete.

See the following pages for more complete summaries of the symposia. Also see the MRS website http://www.mrs. org/ for more detailed program information and abstracts of presentations.
Studies Present Formation, Structure, and Properties of Thin-Film Materials

Symposium A on Evolution of Surface Morphology and Thin-Film Microstructure provided a forum for discussions on fundamental issues in the formation of thin films that have broad implications in materials research. The synthesis of thin films of high crystalline perfection are often a necessary first step for exploring novel physical properties and new applications of electrical ceramics and magnetic films. B. Carter (Univ. of Minnesota) discussed the importance and potential control of substrate surface steps and facets for the growth of epitaxial oxides. Invited talks by H. Zabel (Ruhr-Univ.), J. Hamilton (SNL), G. Betz (Tech. Univ. Wein), and D. Pierce (NIST) took an atomistic look at the formation of metastable phases and of morphology during metal-on-metal growth.

Polycrystalline texture is an important concern in many applications of thin-film materials; fundamental issues involved in the selection of preferred orientation and competitive grain growth during film deposition are receiving increased attention. Film stress, anisotropy of elastic constants, and energetic deposition all play an important role in this complex problem. S. Yalisove (Univ. of Michigan) showed how oblique deposition can create preferred in-plane texture on amorphous substrates; and T. Diaz de la Rubia (LLNL) reviewed recent progress in large-scale computation modeling of metal film deposition in high aspect-ratio geometries.

Real-time studies of surface dynamics using LEEM and synchrotron radiation provide insights on the nanometer-scale physics of crystal surfaces. Much of the discussion of strain effects on morphology and composition also dealt with mesoscopic phenomena: alloy segregation in III-V superlattices, morphology of a-Si/c$\mathrm{Si}$ interfaces, and theoretical treatments of electromigration and the morphology of strained layers.

Symposium Support: KLA-Tencor, Digital, Komag, and Park Scientific.

\section{Debate Ensues About Kinetic and Energetic Effects on Strained-Layers- Produced Nanocrystals}

Symposium C on Self-Organized Nanostructures was organized in a somewhat nontraditional way. Only $1 / 3$ of the submitted abstracts were accepted for presentation, with each oral presentation given 30 minutes. The remaining papers were presented in a poster session. This workshop format allowed more ground to be covered by each individual speaker, which 
generated greater interest in the talks than anticipated from the total number of accepted contributions.

This field has become prolific with significant progress in many areas. In the chemical synthesis of nanocrystals, researchers have demonstrated remarkable size uniformity by optical absorption and luminescence, have observed metalinsulator transition in metal-quantum-dot films, and have successfully doped nanoclusters with rare-earth atoms.

On the growth of strained layers producing arrays of nanocrystals, a debate on the importance of kinetic and energetic effects was the subject of many talks, where real-time STM, real-time x-ray scattering, and scanning probe techniques were used to understand the growth transition from uniform layers through the various morphologies observed in the Ge:Si system. Theoreticians also contributed actively to the discussion, with both dynamic and equilibrium approaches offered to explain experimental observations. The characterization of the electronic properties of strained InAs islands grown on $\mathrm{GaAs}$ revealed many interesting experiments, again demonstrating remarkable uniformity in ensembles of nanocrystals and good agreement with theory. Nevertheless, it was shown that as the number of investigated nanostructures decreased, external influences, such as random distribution of dopants in contacts, become extremely important.

The overall feel was that the initial exploration phase is nearly complete and researchers are now facing challenges in many areas. Considering the $20+$ years devoted to the development of crystal growth of high mobility transistors, lasers, and resonant tunneling diodes, one could say that this field is only at its infancy, and much is still to be discovered and improved to achieve rational use of nanocrystals.

Symposium Support: HP.

\section{Nitride Semiconductors Successes Culminate with Commercially Feasible GaN Laser Diodes}

(See MRS Proceedings Volume 482)

Symposium D wrapped up a year of record success for nitride semiconductors. This meeting also broke record of attendance to gatherings in this field, with over 250 presentations and more than twice that in peak attendance. S. Nakamura (Nichia) was honored in timely fashion by the Society's award of the MRS Medal for his achievements commercializing green and blue GaN LEDs and shortly thereafter blue diode lasers. Nakamura has recently announced $10,000 \mathrm{~h}$ of extrapolated $\mathrm{cW}$ blue laser operation at room temperature

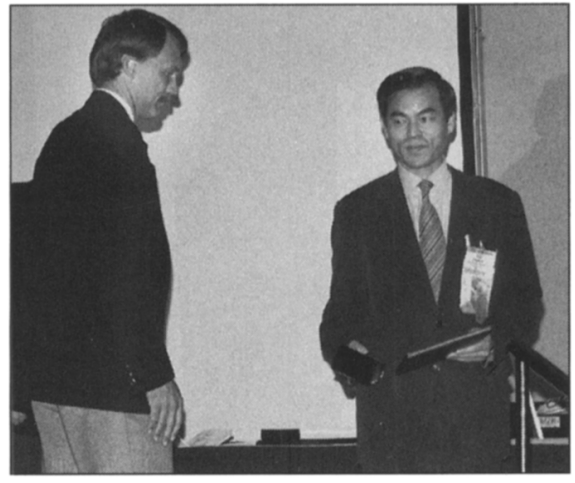

Shuji Nakamura of Nichia Chemical Industries Ltd. (right) receives the 1997 MRS Medal from MRS Secretary Kevin S. Jones (Univ. of Florida) at the 1997 MRS Fall Meeting in Boston. At the end of his talk "III-Nitride Lasers and Optoelectronic Devices," presented as a Symposium $X$ talk for the nonspecialist, Nakamura demonstrated the laser by shining it on specific phosphor-coated papers of different colors. He also demonstrated the $L E D$ s including a pen with the blue LED embedded in a transparent case.

and his firm will shortly begin shipment of prototypes to selected customers. Appropriately, the symposium was dedicated to Jacques Pankove (Astralux), who invented the GaN LED while at RCA Laboratories in the early 1970 s and who is regarded as the father of the nitride semiconductor field.

I. Akasaki (Meijo Univ.) kicked off the program with a plenary lecture on "the evolution of nitride semiconductors" which traced the 30-year history of GaN research. In an enlightening talk, Akasaki described the major milestones that culminated this year with the demonstration of commercially feasible $\mathrm{GaN}$ laser diodes. Epitaxial lateral overgrowth (ELOG) is responsible for the latest progress reported by Nakamura. ELOG is performed by interrupting the growth of the GaN film and introducing $\mathrm{a} \mathrm{SiO}_{2}$ layer which is lithographically patterned into $2-\mu \mathrm{m}$ wide stripes. When deposition is resumed, GaN at first grows only between the stripes where the previous $\mathrm{GaN}$ is exposed, and later out over the $\mathrm{SiO}_{2}$ pads, eventually coalescing with the adjacent ELOG layer. K. Hiramatsu (Mie Univ.) gave an overview of the ELOG technique which was first demonstrated in his laboratory, while T. Zheleva (North Carolina State Univ.) and $A$. Kimura (NEC) reported their recent results in this area. Another important topic was the stability of InGaN in quantum wells. S. Chichibu (Science Univ. of Tokyo) and A. Hangleiter (Univ. of Stuttgart) discussed phase separation in InGaN quantum wells and emphasized the importance of the piezoelectric effect in optical transitions. Significant progress in understanding the materials growth and properties as well as theoretical studies of surfaces and interfaces were presented.

A notable event in the preceding year was that six groups, Toshiba, Cree, Fujitsu, UC-Santa Barbara, Xerox, and Sony, (through October 1997) announced laser operation in nitride semiconductors (Nichia had announced such a milestone in late 1995). All of the groups reported their results on Friday morning, providing attendees with an excellent overview of the present state-of-the-art. L. Sugiura (Toshiba) presented a new inner stripe diode laser geometry. K. Doverspike (Cree) talked about GaN lasers grown on the $\mathrm{Si}$ face of $6 \mathrm{H}-\mathrm{SiC}$ capable of $\mathrm{CW}$ operation.

A tutorial session entitled, "Industrial Applications of GaN Lasers," comprised of invited speakers representing the printing, optical storage, and display industries was held. Many participants felt that much success and maturity have arrived to the field in the past three years, and that impending commercialization forecasts a revolution in the lighting, optical storage, printing, and display technologies based on the recent successes with the nitride semiconductors.

Symposium Support: Nichia, Thomas Swan, Aixtron Semiconductor Tech. GMBH, Toyoda Gosei, Morton Int'l, Renishaw, EPI Chorus, EMCORE, SVT Assoc., MMR Tech., Rockwell Int'l., SULA Tech., Bede Scientific, Siemens, and Lake Shore Cryotronics.

\section{Diamond, GaN, SiC Follow Si in Power Electronics Applications}

(See MRS Proceedings Volume 483)

Power electronics based on innovative Si device design or wide bandgap materials such as $\mathrm{SiC}$, diamond, or $\mathrm{GaN}$ is finding interest for new generations of electronic devices operational at much higher voltages and temperatures than conventional lower power transistors and ICs. Improved bulk and epitaxial growth and processing, processing, device design and circuit architecture, bonding, testing, and packaging are necessary for realizaion of new applications.

E. Brown (DARPA) kicked off the symposium with an overview of the needs for ultrahigh power switches in defense and utility power management. These devices are needed over a wide range of current and stand-off voltages, with a target of 25 $\mathrm{kV}, 3 \mathrm{kA}$ within three years for an existing DARPA program. B. Skromme (ASU) gave an overview of applications of high 
power switches in the electric power utility industry, and J. Casady (NorthropGrumman), J. Davidson (Vanderbilt Univ.), and M. Shur (RPI) reviewed SiC, diamond, and GaN power devices, respectively. J. Zolper (SNL) convincingly described the advantages of JFETs for some of these applications, based on the separation of the electrical and metallurgical junctions. T.P. Chow (RPI) and C. Weitzel (Motorola) presented a comparison of device results in the different materials systems, pointing out the greater maturity of $\mathrm{SiC}$, along with the promising nature of $\mathrm{GaN}$ with its availability of a heterostructure and its good transport properties. For some devices the direct gap of GaN may be an issue because of the short minority carrier lifetimes, but it may be possible to overcome with the use of even wider gap indirect bandgap alloys such as AlGaN. P. Neudeck (NASA) showed some wonderful results on the effect on breakdown voltage of dislocations in $\mathrm{SiC}$ junction devices. $\mathrm{R}$. Kopf (Bell Labs., Lucent Tech.) talked about advanced III-V bipolar transitors, while H.P. Maruska (Implant Sciences), M. Ostling (KTH), and M. Fu (MHI) described some recent advances in process technology.

Clearly Si will continue to dominate most power electronics applications for the next decade, while $\mathrm{SiC}$ is by far the most mature of the newer materials technologies. The latter work has been funded mostly by the defense area in the United States and by corporations in Europe. It is likely that hybrid $\mathrm{GaN} / \mathrm{SiC}$ devices will

\section{Poster Prizes Awarded at the 1997 MRS Fall Meeting}

The 1997 MRS Fall Meeting Chairs Harry A. Atwater, Dean W. Face, Peter F. Green, and A. Lindsay Greer continued the program initiated by the 1997 MRS Spring Meeting chairs to award prizes for best posters each evening. Prize recipients from poster sessions at each hotel received $\$ 500$, a certificate, and the honor of having the winning

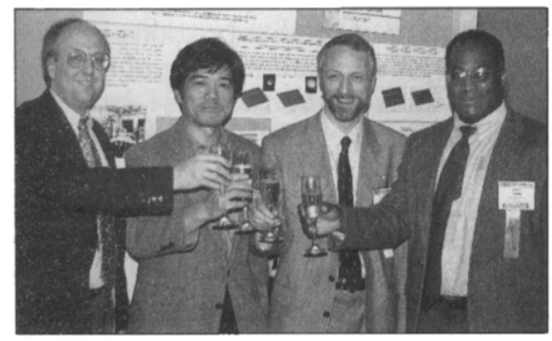

Thursday (December 4) Poster Award recipients at the Westin Hotel: SiteControlled inAs-DOT/GaAs Structures Fabricated by in Situ EB Lithography and Self-Organized MBE Growth, $T$. Ishikawa, S. Kohmoto, and K. Asakawa (Tsukuba Laboratories), (C5.34).

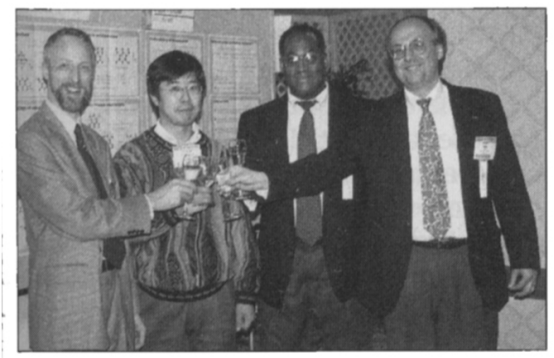

Tuesday (December 2) Poster Award recipients at the Sheraton Hotel: First Principles Study of Interfacial Reaction Atomic Process at Silicon Oxidation, $H$. Kageshima and K. Shiraishi (NTT Basic Research Labs., Japan), (\$5.10)

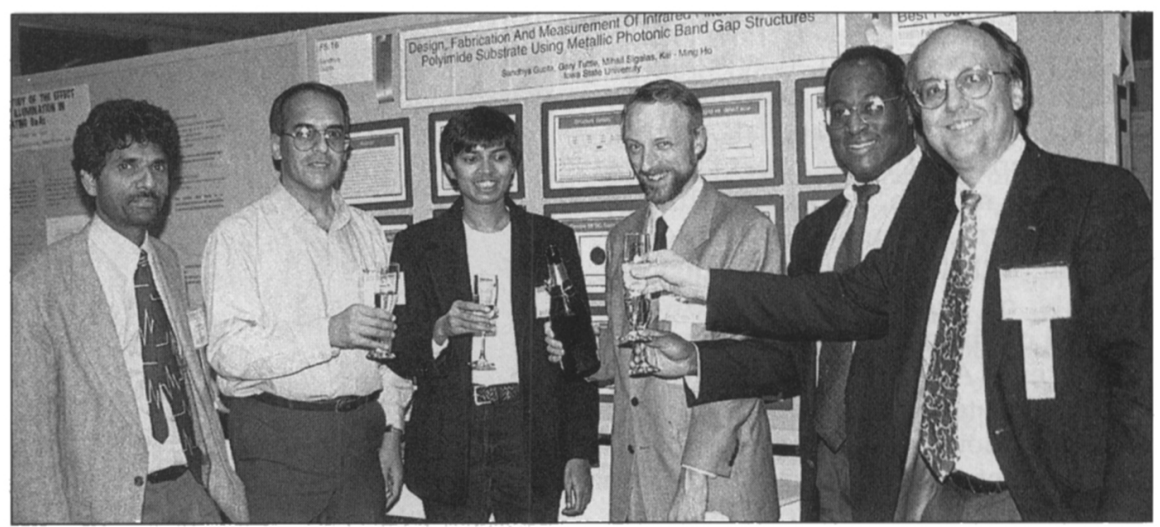

Tuesday (December 2) Poster Award recipients at the Marriott Hotel: Design, Fabrication and Measurement of Infrared Filters on a Flexible Polyimide Substrate Using Metallic Photonic Bandgap Structures, S. Gupta, G. Tuttle, M. Sigalas, and K-M. Ho (lowa State Univ.), (F5.16).

poster displayed in the main hallway at the Marriott Hotel/Copley Place for the remainder of the Meeting. Each recipient was toasted with a glass of champagne by the meeting chairs. Poster Award recipients not shown are Monday (December 1): Studies of the Inorganic Semiconductor-Conjugated Polymer Interface: A Variable Barrier, ShottkyType Diode, M.C. Lonergan, C.T Cooney, and J.A. Myers (Univ. of Oregon), (J3.55); Polydomain Structures of Epitaxial $\mathrm{PbTiO}_{3}$ Films on $\mathrm{MgO}$ and $\mathrm{SrTiO}_{3}$ Substrates, S.P. Alpay A.S Prakash, S. Aggarwal, R. Ramesh, and A.L. Roytburd (Univ. of Maryland), and P. Shuk and M. Greenbalt (Rutgers Univ.), (U4.6); Tuesday (December 2): Towards New Metallo-Supramolecular Assemblies and Polymers, U. Schubert, C. Weidl, and M. Eigner (Tech. Univ., Müchen), and Jean-Marie Lehn (Univ. Louis Pasteur, Strasbourg), (N5.1); In Situ Observation of Atomic SelfOrganization Processes in Xe Nanocrystals Embedded in Al, K. Furuya, M.
Song, K. Mitsuishi (National Research Institute of Metals, Japan), R.C. Birtcher, C.W. Allen (ANL), and S.E. Donnelly (Univ. Salford, UK), (KK6.28); See High $\mathrm{T}_{c}$ : Visualization of Cuprate Superconductors, J. McDevitt, C.E. Jones, C.T. Jones, and S. Warren (Univ. of TexasAustin), (OO2.11); Wednesday (December 3): Large-Area Deposition of Biaxially Textured YSZ Films by Using an IBAD Technique, J. Wiesmann, J. Dzick, J. Hoffmann, K. Heinemann, and H.C. Freyhardt (Univ. of Goettingen), (T8.29); Accelerated Corrosion of Stainless Steel Below $923 \mathrm{~K}$ with the Presence of Molten Carbonate, K. Ota, K. Toda, N. Motochira, and N. Kamiya (Yokohama National Univ.), (Y8.1); and Thursday (December 4): Dielectric and Structural Properties of (100) $\mathrm{KTa}_{x} \mathrm{Nb}_{1-x} \mathrm{O}_{3}$ Films Grown on $\mathrm{MgO}$

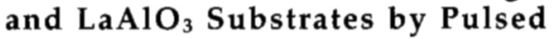
Laser Deposition, W. Chang, A. Carter, J. Horwitz, S. Kirchoefer, J. Pond, D. Chrisey, and K. Grabowski (NRL), (U14.3). 
have a role due to the need for high-thermal conductivity substrates for thermal management. Diamond appears to be trailing because of the difficulty in $n$-type doping, but in principle its properties are better suited to high-temperature applications than many other materials. This was covered by J. Butler (NRL) and R. Singh (Univ. of Florida). Reviews by R. Zehringer (ABB, Switzerland), H. Schulze (Siemens AG), and G. Watchuka (Munich) described the state of the art in various areas of $S i$ and $\mathrm{SiC}$ technology.

Symposium Support: EPRI.

\section{Materials, Physics, Devices, and Systems Converge on Infrared Applications \\ (See MRS Proceedings Volume 484)}

Research into heterostructures for infrared detectors and lasers was particularly well-represented, with significant contributions from both the III-V and IIVI communities, in Symposium F on Infrared Applications of Semiconductors. Key representatives of virtually all major research areas in this field came together, with presentations spanning work on materials, physics, devices, and systems.
Highlights included a review of rapid progress in 3-13 $\mu \mathrm{m}$ quantum cascade lasers by F. Capasso (Bell Labs., Lucent Technologies), reports of improved II-VI detectors promising near-room-temperature and multispectral operation, and reviews of novel negative luminescent devices developed at DRA, UK. Symposium awards for best-contributed presentations were given to J.R. Meyer (NRL) for work on mid-ir VCSELs and R. Gass (Univ. of Cincinnati) for modeling of selective compositional mixing in $\mathrm{Al} / \mathrm{GaAs} / \mathrm{GaAs}$ superlattices. Sympo-

\section{McSween Gives Plenary Presentation on Materials Aspects of Mars Pathfinder Mission}

Harry Y. McSween, Jr. (University of Tennessee-Knoxville) presented the plenary talk on the materials science components of the recent Mars Pathfinder mission, the site of which is now known as the Sagan Memorial Station. While addressing various aspects of the mission, McSween focused on the alpha proton x-ray spectrometer (APXS), an instrument designed to test the composition of the soil and various rocks that the Rover, the mobile robot, was able to examine. With APXS, three kinds of interaction with matter occur: alpha backscattering, production of protons from alpha-proton reactions, and excitation of $x$-rays. This mission provided the first analyses of rocks on the martian surface and additional soil analyses to compliment those of the earlier Viking missions.

The December 5, 1997 issue of Science carries six reports along with an overview of the Pathfinder mission, including McSween's article co-authored with R. Rieder, H. Wänke, J. Brückner, and $G$. Dreibus from Max-Planck-Institut für Chemie, T. Economou and A. Turkevich from Enrico Fermi Institute, and T. Crisp from the Jet Propulsion Laboratory, entitled "The Chemical Composition of Martian Soil and Rocks Returned by the Mobile Alpha Proton XRay Spectrometer: Preliminary Results from the X-Ray Mode." McSween discussed the compositions of six soils and five rocks at the Ares Vallis landing site. According to this report, the soils were generally lower in sulfur and higher in titanium than found in the Viking soils. The rock analyses show higher contents of aluminum, silicon, and alkali and lower contents of magnesium than previously studied martian meteorites. The scientists state that the "compositions of the 'soil-free rock,' Shark, and Barnacle

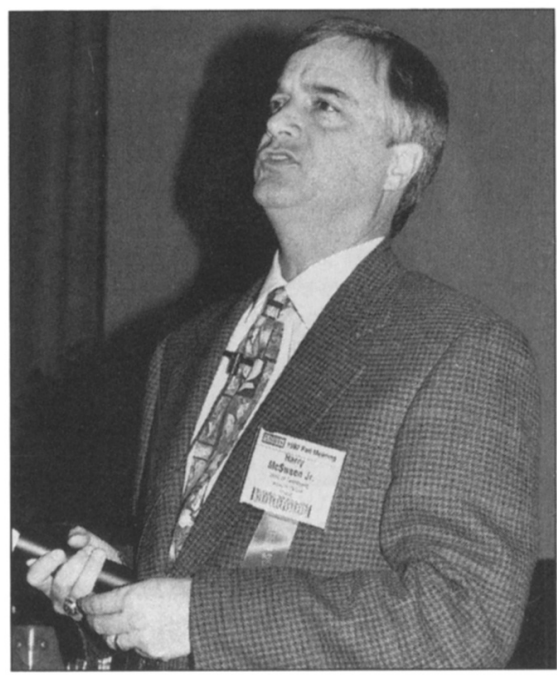

Harry Y. McSween, Jr. of the University of Tennessee-Knoxville, presents the Plenary Talk on Monday evening on "Materials Research via Mars Pathfinder" at the 1997 MRS Fall Meeting in Boston.

Bill may provide a more representative sampling of this [martian] crust than does the only ancient martian meteorite, the ALH84001 pyroxenite," which was discussed in a Symposium $X$ talk at the 1997 MRS Spring Meeting by S. Clemett (Stanford Univ.) (see MRS Bulletin, July 1997, page 57).

According to M.P. Golombek (JPL) who co-authored the Overview published in Science, "The rocks...were basaltic or volcanic rocks, with granitelike origins, known as andesitic rocks. The high silica or quartz content of some rocks suggests that they were formed as the crust of Mars was being recycled, or cooled and heated up, by the underlying mantle. Analyses of rocks with lower silica content appear to be rich in sulfur, implying that they are covered with dust or weathered. Rover images show that some rocks appear to have small air sacks or cavities, which would indicate that they may be volcanic. In addition, the soils are chemically distinct from the rocks measured at the landing site." Chemical analyses of more than 16 rocks and studies of different regions of soilalong with spectral imaging of rock colors, textures, and structures-have confirmed that these rocks have compositions distinct from those of the martian meteorites found on Earth.

As of September 1997, the rover traveled a total of about $100 \mathrm{~m}$ in 230 commanded maneuvers, carried out soil mechanics and technology experiments, and explored about $250 \mathrm{~m}^{2}$ of the martian surface.

During the plenary session, McSween mentioned that magnets were placed on the foot of each rover ramp in order to collect airborne magnetic particles. According to Golombek, the dust collected "is bright red, with magnetic properties that are similar to that of composite particles. A small amount of the mineral maghemite has been deposited almost like a stain or cement." According to S.F. Hviid et al.'s article in Science, the particles are moderately magnetic.

As an aside to the scientific implications, McSween, in his plenary address, referred to another benefit of the Pathfinder mission: News of the mission attracts the general public, and children in particular, to science.

More information, images, and rover movies from the Mars Pathfinder mission are available on various websites, including http://cnn.com/TECH/9706/ pathfinder/ and http://www.jpl.nasa. gov/. 
sium poster awards were presented to $\mathrm{E}$. Abramof (INPE-LAS, Brazil) for MBE growth and $x$-ray characterization of $\mathrm{PbTe} / \mathrm{SnTe}$ superlattices and to K.T. Stevens (West Virginia Univ.) for ENDOR characterization of the zinc vacancy in $\mathrm{ZuGeP}_{2}$. In addition, S. Gupta (Iowa State Univ.) was selected as one of the MRS poster session award recipients for her work on design, fabrication, and characterization of infrared filters employing photonic bandgap structures (see sidebar on poster awards in this article). The Symposium also featured an excellent presentation on 75-300- $\mu$ m-doped Ge detectors for which D.R. Chamberlin (LBNL) was named a finalist in the MRS Graduate Student Awards.

Symposium Support: Air Force Research Laboratory (PL/NTMR), Air Force Research Laboratory (PL/LIDA), and Air Force Office of Scientific Research.

\section{Enhancement of Electronic Transport Properties Needed for Visible Light Emission in Si-Based Optoelectronics (See MRS Proceedings Volume 486)}

Tremendous development of siliconbased optoelectronics has taken place in the last few years, as evidenced from Symposium $\mathrm{H}$ on Materials and Devices for Silicon-Based Optoelectronics. The search for efficient optical functions in Si has driven intense research on a large variety of materials and device structures giving rise to several major developments, new promising approaches, and to potential commercialization of low-cost Si-based photonic devices. The physical properties and optical performances of various materials (such as nanocrystals, porous $\mathrm{Si}$, Erdoped $\mathrm{Si}$, and $\mathrm{SiGe}$ ) are now reasonably well-understood and the issues to be disentangled in order to achieve efficient device performances have been elucidated. The preservation of a proper passivation and the enhancement of electronic transport properties has been recognized as the major limiting steps to improve the efficiency of visible light emission from nanostructures (currently at $0.1 \%$ level). Impact excitation of $\mathrm{Er}$ ions in $\mathrm{Si}$ junctions or e-h recombination in Er-doped microcavities have been shown to provide an efficient and even modulable (up to $5-10$ $\mathrm{MHz}$ ) light emission in the near infrared. In this wavelength range, the synthesis of iron disilicide (a new direct bandgap material) in Si holds high promises. It has been shown that $\mathrm{SiGe}$ quantum wells, $\mathrm{SiGe}$ films on buffered Si, and SnGe alloys could be efficiently used for detection in the near infrared once dark current problems are solved. The $\mathrm{Si} / \mathrm{SiO}_{2}$ system has been recognized as ideal for highly con- fined waveguides and microphotonics components (due to the high refractive index contrast) and for the fabrication of quantum wells and resonant tunneling structures. Finally, it has been shown that efficient integrated modulators (using $\mathrm{BaTiO}_{3}$ films for modulation speed in the $\mathrm{GHz}$ range) and optically pumped amplifiers (using Er-doped $\mathrm{Al}_{2} \mathrm{O}_{3}$ ) holds promises for Si-compatible optoelectronics since both $\mathrm{BaTiO}_{3}$ and $\mathrm{Al}_{2} \mathrm{O}_{3}$ thin films of optical quality can be deposited or grown on a $\mathrm{Si}$ substrate.

Symposium Support: TI, CNR-IMETEM, and SGS-Thomson Microelectronics.

\section{Cadmium Zinc Telluride Grown by High Pressure Bridgeman Method Capitalizes Development of Radiation Detectors}

(See MRS Proceedings Volume 487)

The growth in commercial interest as well as the technical progress achieved in the development of systems for x-ray and gamma-ray spectroscopy and imaging contributed greatly to the sense of excitement felt at Symposium I on Semiconductors for Room-Temperature Radiation Detector Applications. This symposium continues a series of meetings devoted to this topic held every two years alternating between Europe and the United States. The bulk of the work in this field now centers on cadmium zinc telluride grown by the high pressure Bridgeman method; however, considerable efforts reported related to other materials, most notably cadmium telluride, silicon, and mercuric iodide. A report on the growth of cadmium zinc telluride by more standard Bridgeman techniques drew considerable interest as did a number of talks which focused on the optimization of device performance either through materials improvement, fabrication process development, or device design. A great deal of work is now centered on the material and fabrication process optimization for imaging systems. The imaging systems described at the symposium were based on cadmium zinc telluride, silicon, or silicon coupled to higher atomic number materials such as lead iodide. Many companies are actively developing and marketing materials, devices, and imaging systems. Systems for medical applications appear to be most commercially successful at present though applications

\section{http://www.nsf.gov/}

The main gist of the National Science Foundation (NSF) panel presentation to an audience of 70 about how to write and submit materials research proposals is to "Look at the NSF website: http:/ / www. nsf.gov/," the main dissemination of information. The panel, held on Tuesday evening from 5:30 p.m. to 7:00 p.m. followed by an informal drop-in session the next day, presented various aspects of NSF funding. For education, NSF tends to receive more money in the budget than the Foundation originally requests because NSF gives the message to Congress that "education keeps the economy rolling." General audience response was very good with several questions fielded by the NSF staff.

After discussions within MRS/NSF Focus Groups that met during the 1997 MRS Spring Meeting in San Francisco, W. Lance Haworth, Acting Executive Officer of the Division of Materials Research (DMR) at NSF, recognized the need for the Fall Meeting presentation since materials researchers were largely unaware of the grant opportunities and process available through NSF (see MRS Bulletin, July 1997, p. 64 for the MRS/ NSF Focus Groups report). Panelists Thomas A. Weber (DMR Director),
Haworth; LaVerne D. Hess (representative within the Advanced Materials and Processing Cluster); David L. Nelson (within the Base Science Cluster); and Carmen I. Huber (within the Materials Research and Technology Enabling Cluster) suggested helpful hints when describing the proposal process. For example, when submitting a proposal, the researcher could talk with program directors to help determine the correct program for the proposal; otherwise, the researcher actually need not be too concerned about which is the proper program since the directors at NSF will determine and route the proposal to the appropriate place. Researchers should suggest possible reviewers for their proposals along with who not to choose because of personal or professional reasons. The program director selects a reviewer, analyzes the review, and makes a decision whether to provide the grant. Generic criteria for reviewers is available on the NSF website. Proposal deadlines for 1998 are also posted on the world wide web at http://www.nsf. gov/home/grants.htm or contact NSF at 4201 Wilson Blvd., Arlington, VA 22230; 703-306-1234; TDD 703-306-0090. 
in basic science, environmental monitoring, industrial applications, and international treaty verification are actively being pursued as well.

Symposium Support: AMPTEK, SNL, Spire, Johnson Matthey Electronics, RMD, Noranda Advanced Materials, CEA-LETI, and Bicron.

\section{Organic LEDs Represent Near- Commercial Status of Solid-State Materials}

(See MRS Proceedings Volume 488)

The presentations of Symposium J again attest to the fact that research involving electrical, optical, and magnetic properties of organic solid-state materials continues to grow both in scope and technological importance. Early studies of charge transport in conducting polymers have evolved from the elucidation of fundmental structure/function relationships to applications as batteries, simple electrical devices such as diodes, chemical sensors, antistatic coatings, microwave and millimeter wave absorbing materials, and photochromic devices. A particularly exciting evolution has been the discovery and development of
OLEDs which appear to be nearing commercialization in an amazingly short period of time. This application is of particular interest because both electrical and optical properties must be considered. Moreover, nanostructure control is important for OLEDs and nanoscale architectural engineering has been an increasingly important theme of the symposium. Indeed, not only has the study of conjugated (quasi-delocalized) electrons in organic solid-state materials resulted in interesting physical properties and device applications but the desire to exploit these properties has promoted the development of new synthesis and processing methodologies to achieve special nanoscale and microscale structures.

Symposium Support: United Microelectronics, President Enterprises, and International Specialty Products.

\section{Materials Science of the Cell Symposium Introduced to MRS Meeting}

(See MRS Proceedings Volume 489)

Biological cells have evolved intriguingly complex materials whose architec- ture surpasses by far most synthetic materials. Understanding the properties and the processing routes of macromolecular assemblies is crucial for an understanding of cell function. Simultaneously, knowledge of biological optimized solutions for materials problems is inspiring new approaches for materials. Symposium K on Materials Science of the Cell aimed to provide a platform for a multidisciplinary discussion of biomolecular materials. The multidisciplinary nature of the topic was reflected in the wide range of research presented, including biology, chemistry, physics, materials science, and biomedical engineering.

H.C. Berg (Harvard Univ.) reported on the mechanics of the rotary motor that drives the flagella of $E$. coli bacteria, an example of nanotechnology. All the macromolecular components of the motor are now known as well as the regulatory biochemistry. Despite much progress in the micromechanical characterization of single motor units, however, much still remains mysterious about how a "current" of protons drives this motor.

\section{That's Edutainment!}

Students of Russell Pinnizzotto (Univ. of North Texas and Zzotto Enterprises) finish their last few class sessions with a board game called Fab Line ${ }^{\mathrm{TM}}$. Similar to the popular game of Monopoly, Fab Line $^{\mathrm{TM}}$ consists of a game board, playing pieces, money, cards, and dice; however, in this S\&T game about the basics of IC fabrication, many players can win. Major technological and economic principles are demonstrated as players race their ICs, diodes, or transistors around the board while avoiding such disasters as "Acts of God" (unexpected technical difficulties) while making decisions about whether to delay production and spend resources on R\&D. Along with Acts of God cards are a deck of cards consisting of questions that players must answer before they can continue playing. Various questions can be used in the deck so that players can tailor the educational level. The questions typically lead to a discussion. During his presentation in Symposium OO, Workshop on Materials Education, Pinnizzotto said that the game works best with four to eight players.

Symposium $0 \mathrm{O}$ also included sessions on innovations in materials curricula and computers in materials education, including an interactive poster session demonstrating software and teaching resources. D. Dizon (Lawrence Tech. Univ.) dis-

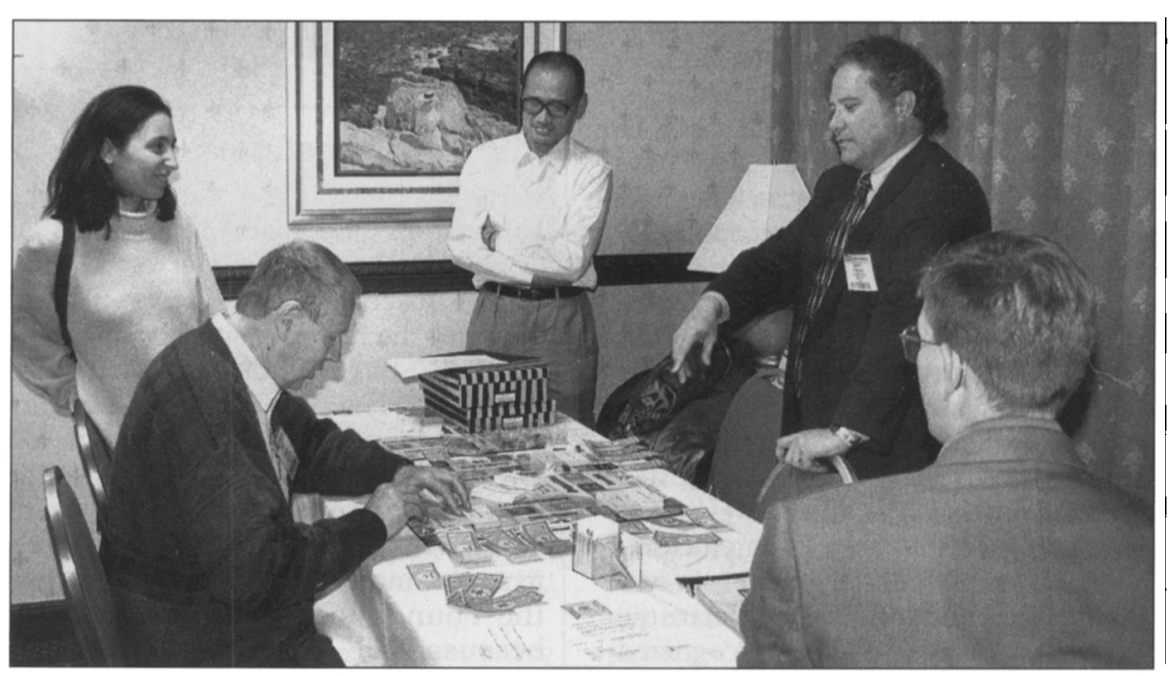

Russell Pinnizzotto of Zzotto Enterprises (standing right) demonstrates his S\&T IC fabrication board game Fab Line ${ }^{\mathrm{TM}}$ during the Symposium OO, Workshop on Materials Education, interactive poster session at the 1997 MRS Fall Meeting in Boston.

cussed the development and assessment of on-line courseware. He suggested that initial uses of the internet were largely in place of existing tools such as bulletin boards or a message center. More recently, however, educators have begun to recognize the potential of the Internet as a course delivery system which can only be realized if accompanied by a paradigm shift in how educators view teaching and learning. A few speakers described online courses such as a course for $\mathrm{K}-12$ in which students access real-time databases from the Internet (E.A. Friedman, CIESE).

Papers from this symposium will appear in a special issue of the Journal of Materials Education.

Symposium Support: NSF Advanced Technology Education Program and Univ. of Washington. 
D. Morse (UC-Santa Barbara) displayed the nanoscale architecture of biominerals deposited by abalone and diatoms which are composites of proteins and tightly controlled inorganic nanocrystals. M. Toner (Harvard Medical School) spoke about using patterned and functionalized surfaces for liver tissue engineering where the control over cellcell interactions between different types of cells can be used to approach the complex structures of natural tissue. H.E. Gaub (Ludwig-Maximilians Universität, München) demonstrated direct measurement of protein unfolding using the AFM tip to pull apart the two ends of the amino acid backbone of a protein. $U$. Bockelmann (Ecole Normale Superieure, Paris) directly measured the sequence dependent interaction between two complementary DNA strands by prying apart the DNA double helix with a glass micropipette. D. Branton (Harvard Univ.) measured the ionic conductance of a membrane channel protein while a single DNA strand is pulled through by an electric field, offering an original approach to DNA sequencing.

Symposium Support: Chroma Tech., Whitaker Foundation, and Elsevier.

\section{Concepts and Tools of Complex Fluids Explored in Area of Biomaterials}

Complex fluids are liquids containing self-assembled structures of length scales that are intermediate between the molecular and macroscopic. Examples include amphiphilic phases, gels and polyelectrolytes, colloids, or liquid crystals. Due to their intermediate-length scales, complex fluids are subject to both molecular and macroscopic forces, and thus pose basic scientific challenges. Technologically, they have a wide range of applications, ranging from lubricants and coatings to cosmetics and foods, and from optical switches to electronic displays. While these materials are widely used in technology, their fundamental properties are often poorly understood. As a result, optimization of their usage is haphazard at best, and often suffers severely from the lack of understanding of underlying principles.

Addressing these fundamental issues will undoubtedly lead to discoveries, both scientifically and in terms of broadening their utility. Efforts are increasingly turning to utilizing the concepts and tools of "classic" complex fluids in the study of biomaterials. Indeed, the materials that are of the greatest importance for biology are complex fluids.

Symposium L on Complex Fluids and Biomaterials, the fifth in a series of biennial symposia, brought together a broad

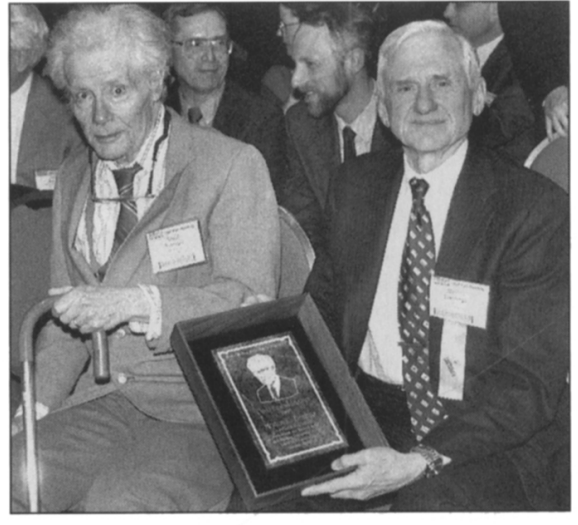

property analysis at the microscopic scale and the manner in which properties at the microscopic level control macroscopic properties. The symposium covered synthesis, processing, interphase/interface, nanostrucutured composites, fractal theory, percolation, fracture, durability, adhesion, toughness, characterization, sensing, and property versus structure issues.

Symposium Support: $A R O$

\section{Use of Degradable and Nondegradable Polymers Rapidly Expanding for Orthopedic Applications}

One of the rapidly expanding areas of biomaterial science and engineering is the design and use of degradable and nondegradable polymers in orthopedic applications. Nondegradable polymers such as poly(ethylene) and poly(methylmethacrylate) have long been studied. Despite their history of study, many questions remain, for example, in such areas as poly(ethylene) wear and effect of polymeric molecular weight, oxidation, and processing. Alternatives to polymeric materials such as ceramics present unique strengths and weaknesses for analysis and study. Biogradable materials such as polylactic acid polymers, polyglycolic acid polymers, polycaprolactone, and various other materials are being studied extensively. In the area of fracture healing, for example, these materials should have sufficient strength to stabilize the bone during healing, degrade quickly enough to prevent stress shielding, and eventually completely disappear without unwanted effects. Many proposed applications for these polymers have been explored including their use as carriers of antibiotics and growth factors for controlled localized release, bone defects fillers, and materials that can provide a scaffold for tissue growth/replacement

Symposium O on Polymers in Orthopedics presented papers that focused on current controversies and horizons for study. These topics include analysis and characterization of polymeric orthopedic materials; polymeric applications for the regeneration of musculoskeletal soft tissues; three-dimensional architecture for tissue engineering; cellular reaction to synthetic and natural polymeric implants for nerve generation; biomechanics of orthopedic polymeric biomaterials; ther$\mathrm{mal}$ and dynamic properties of poly(DLlactic acid) and poly (DL-lactic-co-glyclic acid); reinforcement of biodegradable fracture fixation devices; bone regeneration using bone morphogenetic protein and a drug delivery system; development of biodegradable flexible matrix and biodegradable putty for bone repair; and 
biodegradable blends for controlled drug delivery.

Symposium Support: BIOMET and Johnson \& Johnson.

\section{Modeling Influences Development in Semiconductor, Optical, Magnetic, and Other Materials}

Papers presented in Symposium P on Modeling Across Length Scales for Materials Development demonstrated that all classes of materials have benefited from modeling and how advances in modeling and simulation have been applied toward the development of new materials and provided future directions for the implementation of modeling to accelerate the pace of materials development. Applications of quantum mechanical techniques in the development of semiconductor, optical, and magnetic materials played a key role where the performance of the material was controlled by a single property determined at a specific length and energy scale. Advances have been made in the modeling of metallic materials, particularly at the mesoscale. Coupling these advances with new models for microstructural evolution show the potential for providing the same advances in development of structural materials as those provided in the modeling of semiconductor, optical, and magnetic materials.

\section{Development of Linear-Scaling Methods Increases Tight-Binding Theory Popularity \\ (See MRS Proceedings Volume 491)}

Symposium $\mathrm{R}$ on the Tight-Binding Approach to Computational Materials Science presented three days of leadingedge research on formal developments and applications in electronic studies of materials properties based on the TB approach. Modern TB theory provides a conceptual framework for a physical understanding of the structure of materials and relates the full-scale microscopic, quantum-mechanical computation of materials properties with intuitive chemical and physical arguments. This link between $a b$ initio methods and phenomenological concepts allows one to address a wide range of complex materials issues, and at the same time retain the underlying physics responsible for typical materials behaviors. This symposium brought together researchers working on various aspects of TB theory and on its applications to materials science.

On the formal front, important roads were reported on first-principles TB methodology and its applications to the study of the effects of correlations in

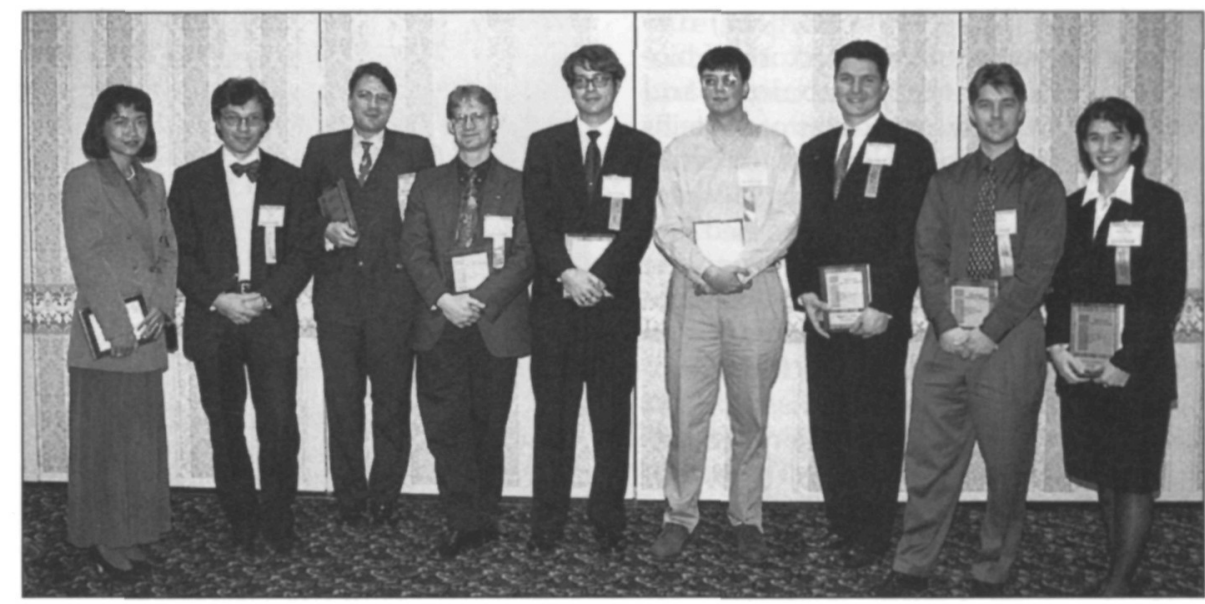

Nine Graduate Student Awards were presented at the 1997 MRS Fall Meeting in Boston. Graduate Student Award recipients are (from left to right) Jinghong Chen (University of Southem Califomia), Stefano Zapperi (Boston University), Michael Natusch (University of Cambridge), Michael C. Wanke (University of Califomia - Santa Barbara), Michael Fasolka (Massachusetts Institute of Technology), Ilya Koltover (University of Califomia-Santa Barbara), Robert C. Mucic (Northwestem University), Stephen A. Empedocles (Massachusetts Institute of Technology), and Lila J. Chamberlain (Massachusetts Institute of Technology).

solids, the development of $\mathrm{O}(\mathrm{N})$ methods in TB-molecular dynamics simulations, and parametrization schemes for use with semi-empirical TB models. Electronic structure theory is on the verge of addressing issues related to macroscopic phenomena such as the mechanical properties of materials by making use of localized basis sets and new electron energy functionals. Recent development of quantum Monte Carlo in combination with TB models were reported. Over the last decade, these types of calculations have made the transition from addressing abstract issues concerning the effects of electron-electron correlations on magnetic and metal-insulator transitions to concrete contact with experiments. Several speakers discussed ways of obtaining prameters for an implementation of a semi-empirical TB approach to materials science. The increased popularity of the TB method is due to the development of linear-scaling methods that allow the use of this formalism in molecular dynamics simulations of large-scale systems.

The application of TB theory to the calculation of materials properties were an important component of the symposium. In this regard, methodology was presented for treating the interaction of light with matter with exciting possible applications to the properties of lasers and other systems. Recent progress in the prediction of the atomic, electronic structure, and magnetic properties of disordered metallic alloys, and in the physics of semiconductors, liquid alloys, alloy sur- faces, and magnetic multilayers were given ample coverage. Recent developments in the calculation of conductivities and other linear-response functions, and new approaches to mean-field theory of alloy stability in periodic and nonperiodic systems were reported. The predictive power of semi-empirical TB in providing a physical picture of the links between bonding, stability, and other properties was illustrated for various systems such as silicides, carbides, amorphous silicon, and nanoclusters. The limits of applicability of TB models in the study of surfaces of bimetallic systems were indicated in connection with equilibrium and dynamical processes. Finally, the structural properties of elemental covalent liquids, such as arsenic and antimony, as well as amorphous covalent materials, such as Ga-As and $\mathrm{Si}$, were described accurately through the use of TB simulations. Overall, the symposium discussed current research issues and the implementation of TB concepts in efficient computational tools which are relevant for addressing the inceasingly complex materials challenge of the future.

Symposium Support: HP, Dept. of Materials Science-Univ. of Milan, MPI-Stuttgart, LLNL, ENEA, CNR-GNSM, and ONR.

\section{HTS Symposium Looks to the Long Term}

As HTS materials come closer to widespread use in real-world applications, one of the issues that must be addressed is the robustness of the superconducting 
devices, and therefore the stability of the materials. Symposium T on Stability of High- $\mathrm{T}_{\mathrm{c}}$ Superconductors was a success in part because it encouraged researchers to remeasure the characteristics of materials and devices made several years ago, thereby creating some of the important lifetime and stability data.

In the thin film sessions, A.C. Anderson (MIT) and J.Z. Wu (Univ. of Kansas) discussed the stability of $\mathrm{YBCO}$ and $\mathrm{Hg}$ based materials with time and thermal cycling. Various groups reported on the exposure of HTS thin films to different solvents, high-temperature and highhumidity conditions. Passivation is clearly important and many groups now use Teflon $A^{\circledR}{ }^{\circledR}$ for this purpose. While it would not pass the Navy's qualification testing (which according to A. Martin of NAWC includes prolonged exposure to seawater), it has protected the junctions at QM (A. Hibbs) and elsewhere.

Results of multiple measurement on Josephson Junctions and SQUIDs, the most sensitive of HTS devices, were reported. For junctions in which the active junction area is covered, inherently or deliberately, the properties of the junctions were stable with time (1.5-3 years) and thermal cycling (see Figure). In some cases an increase in $J_{c}$ was reported, possibly due to oxygen re-ordering under extended room-temperature annealing. M. Dilorio (Magnesensors) showed that the noise level of SQUIDs, an even more stringent test than $J_{c}$ or $R_{n}$, did not change over 30 thermal cyclings and 1.5 years.

In the coated conductor sessions, E.D. Specht (ORNL) showed improved $J_{c}$ prop- erties on thermomechanically textured substrates by controlling substrate grain growth and introducing a new capping $\mathrm{CeO}_{2}$ buffer layer. S.R. Foltyn (LANL) showed improved deposition kinetics of IBAD-processed films by using a thin, rapidly deposited $\mathrm{MgO}$ IBAD layer developed at Stanford University. He also presented new, high $J_{c}$ results on a $12-\mathrm{cm}$ long sample, but variable results on a 100$\mathrm{cm}$-long sample. Wiesmann (Goettingen, Germany) showed new results of 2 $\mathrm{MA} / \mathrm{cm}^{2}$ at $77 \mathrm{~K}$ for $10 \times 10-\mathrm{cm}^{2}$ films deposited by IBAD. These sessions demonstrated that high-performance samples are produced routinely by many laboratories and that the focus is primarily on scale-up.

In the $\mathrm{Bi}-2223$ bulk conductor sessions, researchers presented results on current paths in single filaments, and discussed models of current flow. Modeling of mechanical properties and phase diagram work were also presented. Apparently long lengths are routinely produced by many companies and the focus is primarily on understanding the mechanisms for current transport to improve performance.

In other bulk conductor sessions, researchers reported on $\mathrm{Nd}-123$ stoichiometry experiments that enable crystal growth to occur in air. Reports covered Nd-123 phase diagram work, YBCO growth kinetics, the stages of the YBCO growth process, and methods for joining crystals together.

One of the highlights of the meeting was a special session on the status of HTS commercialization efforts in Japan, Europe, and the United States. The

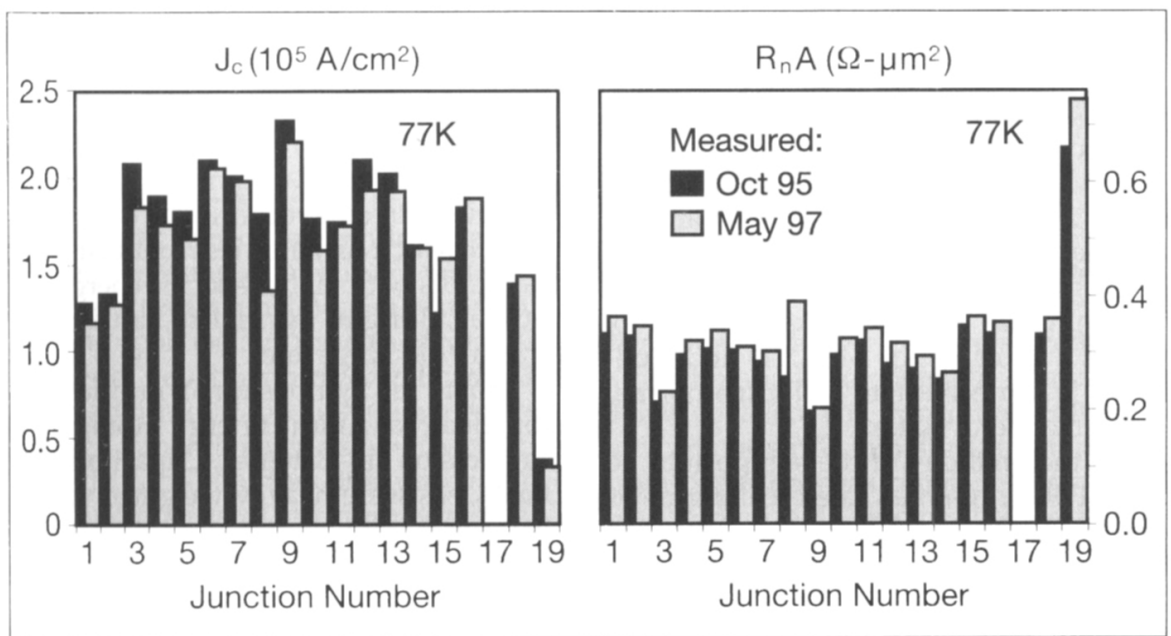

Long-term stability of edge SNS junctions (YBCO/100 $\AA 7 \%$ CO-YBCO). The average $\mathrm{J}_{c}$ and RaA for all the junctions on this chip changed only 1\%. See "HTS Symposium Looks to the Long Term." (Courtesy of J. Talvacchio, Northrop Grumman.) breadth of application activities worldwide is tremendous. S. Tanaka (ISTEC, Japan) reported that the Japanese superconducting Maglev train had just been clocked at over $500 \mathrm{~km} / \mathrm{h}$. Scientists reviewed the status of large-scale applications in Europe and the United States, respectively. Significant projects in cables, transformers, magnets, SMES, fault current limiters, motors, and current leads are being driven by both small and large companies. HTS wire is already good enough for applications according to Schwall; the real driver will be reliability and cost. Rowell (John Rowell, Inc.) stressed the importance of cryogenics and cryopackaging in his report on the Roadmap for HTS Thin Films. According to Rowell, it all begins and ends with cryogenics.

Symposium Support: ANL, ORNL, TRW Space $\mathcal{E}$ Electronics, LANL, Iwate Prefectural Government, and DuPont Superconductivity.

\section{BST, PZT, and SBT Play Key Roles in Development of DRAMs and Ferroelectric Nonvolatile Memories (See MRS Proceedings Volume 493)}

The two applications receiving the most attention at Symposium U on Ferroelectric Thin Films were high-density DRAMs and ferroelectric nonvolatile memories. The DRAM applications use a ferroelectric material in the paraelectric phase (i.e., above the Curie temperature) to provide a high permittivity bit cell capacitor dielectric. BST is the material that is receiving the most attention for DRAM applications. BST is expected to appear in commercial DRAMs at the $1 \mathrm{~Gb}$ and $4 \mathrm{~Gb}$ generations.

The nonvolatile ferroelectric memories on the other hand use ferroelectric materials which are selected to have the Curie temperature well above the operating temperatures of the memory. The built-in or remanent polarization in the ferroelectric crystal lattice is used as a memory element. The materials which received the most attention were the PZT family and the layered perovskite family based on SBT. Talks at the symposium discussed progress in processing and integration of these capacitors in ICs as well as reliability aspects.

The electrode materials also received significant attention. The choice of electrodes can have a dramatic impact on the resulting device performance. Other topics of interest included frequency agile microwave capacitors, piezoelectric sensors and micromechanical devices, and pyroelectric applications.

Symposium Support: Inorgtech, MKS Instruments, Samsung Advanced Institute of Tech., and Motorola. 


\section{Characterization, Transport \\ Mechanism, Strain on Physical \\ Properties Highlighted for Metallic Magnetic Oxides \\ (See MRS Proceedings Volume 494)}

Symposium V on Metallic Magnetic Oxides focused on the advances and challenges associated with moving these materials into technological applications. For this to occur, the physical properties and theoretical mechanisms must be wellunderstood. The symposium was thus organized to focus on the materials characterization, theoretic models of the transport mechanism and devices, and the effect of strain on the physical properties.

Highlights of the symposium included a well-summarized, very encouraging, broad examination of the S\&T of the CMR thin films by T. Venkatesan (Univ. of Maryland). He highlighted their possible applications for TMR and bolometric devices. G. Xiao (Brown Univ.) presented the much-improved data for the tunneling junctions and impressed upon the audience the steady advance in the TMR properties of the manganites. The junctions were beautiful epitaxial-doped La$\mathrm{Mn}-\mathrm{O} / \mathrm{SrTiO}_{3} / \mathrm{La}-\mathrm{Mn}-\mathrm{O}$ heterostructures; Xiao reported that the TMR decreased substantially above $100 \mathrm{~K}$, and correlated that with the decrease in resistance of the devices at that temperature. The decrease in resistance was surmised to be due to thermal activation over the barrier. M. Rajeswari (Univ. of Maryland) explored the possibility of using these materials for uncooled bolometric devices, and explored the characteristics and origin of the $1 / f$ noise that may be a limiting factor in developing bolometric devices.

Both J. Goodenough (Univ. of TexasAustin) and D. Emin (Univ. of New Mexico) provided a broader perspective on the chemistry and physics of the CMR manganite. They discussed insights that have evolved from work predating the recent rediscovery of the manganites. Goodenough discussed the phase diagram in terms of the tolerance factor (average radii), and how it correlated to super-exchange and double-exchange transport mechanisms. Emin discussed the intricacies of polaron physics.

Symposium Support: National Institute for Advanced Interdisciplinary Research, $H P$, and LANL.

\section{Various MOCVD Aspects Covered in Electronic Ceramics Processing} (See MRS Proceedings Volume 495)

Chemical Aspects of Electronic Ceramics Processing (Symposium W) began with a tutorial on Sunday afternoon.

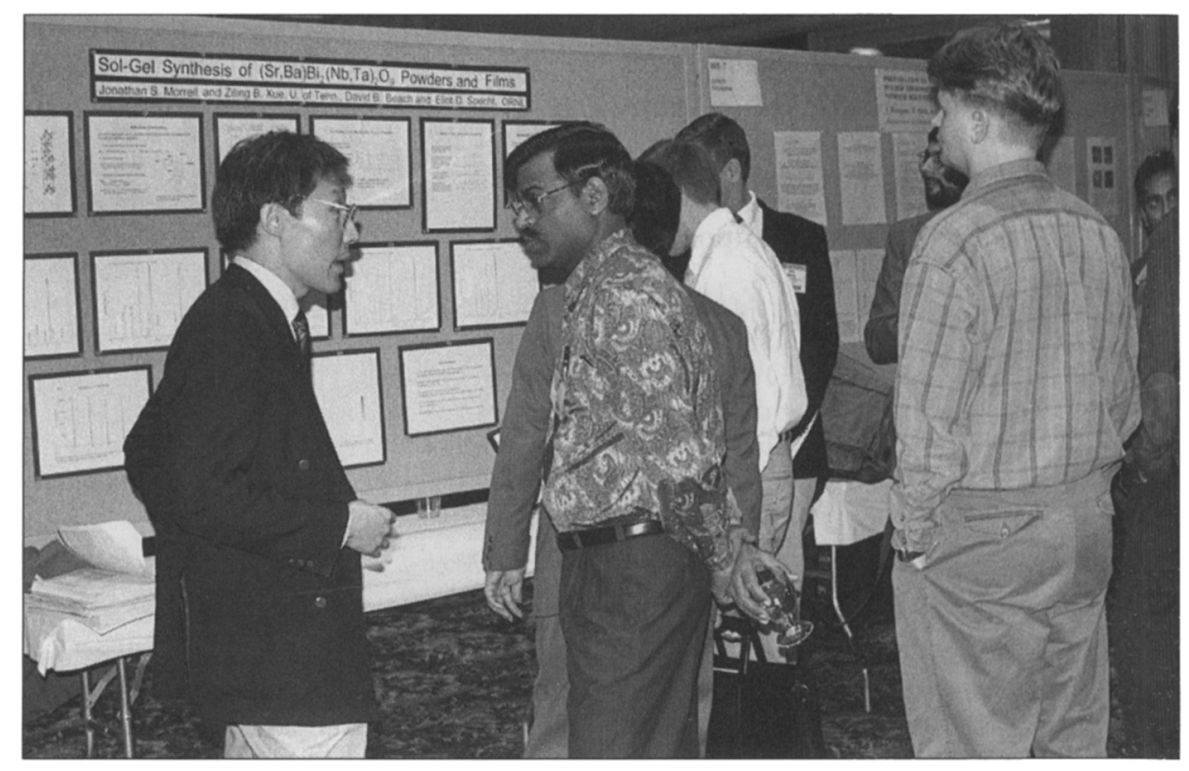

At the 1997 MRS Fall Meeting in Boston, poster sessions were scheduled at all three hotels for the first time, with several symposia holding their own poster presentations.

Instructors T. Marks and B. Wessels, both from Northwestern University, discussed MOCVD, and D. Payne (Univ. of Illinois) discussed sol-gel synthesis of advanced performance, multication electronic ceramics.

The initial day of the symposium included talks on hydrothermal growth of epitaxial oxide films, contact printing of electronic ceramics, and hydrothermal growth of single crystals of GaN. The afternoon session was the first of three focusing on MOCVD, primarily dealing with novel precursors, processing, and applications of oxide ceramics. Notable presentations from the afternoon sessions included talks on MOCVD of conducting transparent oxides and molecular design of precursors.

The second day of the symposium featured a session on deposition of nitrides, on the deposition of buffer layers and active layers for HTS, and on MOCVD. The third day featured talks on design of liquid precursors for MOCVD and studies of the mechanism of hydrothermal growth of perovskites.

On the final day of the symposium, R. Roy (PSU) presented late-breaking news on the use of a three-laser process to alter the structure of a number of materials with a significant increase in performance. The symposium ended with an innovative panel discussion including representatives from industry, academia, and government. The panel discussed drivers for new materials/technologies, smart processing, and "top down" versus "bottom up" synthesis of materials structures.

Symposium Support: NASA Lewis Research Center, MKS Instruments, Inorgtech, Gelest, ONR, NanoPore, CVC Products, Elsevier Science, NYS Center for Advanced Thin Film Tech, and ORNL.

\section{Li Batteries Lead Research on Electrochemical Energy Storage and Conversion}

(See MRS Proceedings Volume 496)

Our energy-hungry world is increasingly relying on new methods to store and convert energy for portable electronics as well as new, environmentally friendly modes of transportation and electrical energy generation. The availability of advanced materials is linked to the commercial success of improved power sources such as batteries, fuel cells, and capacitors with higher specific energy and power, longer cycle life, and rapid charge/discharge rates.

Papers for Symposium $Y$ on Materials for Electrochemical Energy Storage and Conversion II-Batteries, Capacitors, and Fuel Cells were heavily weighted toward lithium batteries, with half of the 140 papers presented discussing various aspects of this rapidly advancing technology. In particular, cathode materials were discussed from the aspect of modeling, new synthesis techniques, and processing technology. Ab initio modeling methods as well as empirical techniques were applied 
to the family of transition metal oxides and sulfides that gave increased understanding of phase stability, lithium diffusion, and the intercalation mechanism. The effect of dopants on the improved capacity retention was explained, and degradation mechanism of capacity loss at elevated temperature was elucidated.

Lithium ion rechargeable battery anode materials were also discussed, with emphasis on carbon and the new family of tin oxides with very high capacity-up to $1000 \mathrm{mAh} / \mathrm{g}$. The intercalation mechanism and $\mathrm{Li}$ bonding sites were the topic of several papers, with new 7Li-NMR techniques identifying both reversible and irreversible lithium binding. Coupled with the semi-empirical modeling calculations on carbon, a fuller understanding of carbon anode materials emerged.

New colloidal deposition techniques and sol-gel processing procedures were described that enable the fabrication of thin solid oxide fuel cells. These developments would decrease the operating temperature, size and weight of fuel cells, making them more cost competitive. In all, the results presented at this symposium gave a deeper understanding of the relationship between synthesis, properties, and performance of power source materials, and gave the encouraging outlook of further increases in performance.

Symposium Support: SKC America, SNL, and NREL.

\section{Electronic Structure of Catalytic Systems Affect Activity and Selectivity (See MRS Proceedings Volume 497)}

Traditional catalysis is undergoing a dramatic change that is reflected in a number of new exciting approaches, some of which were presented at Symposium Z on Recent Advances in Catalytic Materials. The recent advent of STM and STS has allowed researchers to obtain information on the physical and electronic properties of metal clusters supported on metal oxides. Technologies that have been in existence for the processing of electronic materials such as electron beam lithography are now being incorporated into the area of catalysis to produce novel nanostructural catalytic systems with extraordinary properties. Although support materials have been traditionally nonconductors, it is now recognized that the use of structurally tailored and electrically conductive graphite nanofiber and fullerene-based supports can induce some unexpected changes on the catalytic behavior of small metal particles. The concept of activating catalyst surfaces by manipulation of the electronic properties of the substrates was perhaps one of the most fascinating concepts presented at this symposium. Surface acoustic waves and resonance oscillations have been found to have a significant effect on the arrangement and electronic structure of surface atoms and therefore can alter not only the activity, but also the selectivity of a catalytic system. Since the discovery of the unusual catalytic properties of zeolites, oxide catalysts are now being carefully crafted so as to produce materials having extremely well-defined structural properties where the manipulation of pore size is crucial to the activity and selectivity of catalysts for a variety of chemical reactions.

Symposium Support: PSU.

\section{Carbon and Related Amorphous-to- Nanocrystalline Thin Films Significant for Electronic, Optical, Tribological Applications \\ (See MRS Proceedings Volume 498)}

Symposium AA on Covalently Bonded Disordered Thin-Film Materials was held for the first time and indicated the increasing importance of carbon and related amorphous-to-nanocrystalline thin films for use in a wide range of electronic, optical, and tribological applications.

The symposium opened with a series of presentations on the theoretical determination of plausible amorphous diamondlike carbon bonding configurations, followed by a number of talks providing structural, electronic, and optical characterizations with a strong connection to the theoretical structural models. Dissertions on the use of Raman spectroscopy for the in-depth study of these carbon materials were provided by both D.R. Tallant (SNL) and K. Gilkes (East Anglia Univ.). The most intriguing property of these materials is their ability to emit electrons in low electric fields at room temperature, with potential use as coldcathodes for a "leap-frog" flat-panel FED technology. B.F. Coll (Motorola) highlighted the symposium, describing a new stateof-the-art field-emitting material: a $100 \%$ graphitic "nanocoralline" thin film structure grown using a filtered cathodic vacuum arc, producing $>10^{6}$ emission sites per $\mathrm{cm}^{2}$ with low operating voltages, more than sufficient for present display needs.

Other sessions described the production, characterization, and application of boronand carbon-nitride thin films, and three inroom poster sessions completed this wellattended and wide-ranging symposium.

Symposium Support: Balzers Process Systems S.A.

\section{Research on Thermal Spray Materials Addresses Coatings and Spray- and Beam-Processing}

Both the coatings and the materials science communities were represented at Symposium BB on Science and Techno- logy of Thermal Spray Materials Processing, the first such MRS symposium dedicated to thermal spray per se. This symposium also addressed closely allied and complementary spray- and beam-processing technologies with an additional emphasis on direct fabrication of hardware from electronic media renditions of design concepts. Several technologies are under development using this approach, both for structural shapes and electronic components.

Intelligent spray processing and modeling were addressed. Clearly, considerable headway has been made in single splat solidification modeling. Relating these results to advanced diagnostics has allowed a dramatically improved understanding of deposit formation. Modeling and metallographic characterization go hand-in-hand toward a clearer understanding of deposit evolution. SEM and TEM observations by researchers at SUNY - Stony Brook have been related to predicted splat structures, demonstrating that rapid solidification plays the major role in deposit formation. Calculations of the rate of motion of solidification fronts in single splats are consistent with the observed microstructural features of both the single splat disks and the deposits.

Cold spray was reviewed by J.R. Smith (GM), who described the physics of particle acceleration mechanisms. He characterized the relation between spray parameters and coating properties. Cold spray differs from HVOF processes, which involve heating of the particle by a supersonically moving burning gas. Relative to nontraditional spray techniques, a session was convened on water-stabilized plasma spray. This liquid plasma operates at 160 $\mathrm{kW}$ and above and allows materials through-put increases by a factor of 20-30 over normal plasma spraying.

An important aspect of thermal sprayed coatings are process-related imperfections, such as cracks and voids, which determine a number of critical physical properties (e.g., thermal expansion coefficient, thermal conductivity, and modulus). Mechanical properties will also be significantly influenced by the imperfection structure. A number of papers were presented on research done at NIST on small-angle neutron scattering of plasma-sprayed ceramics, such as alumina and partially stabilized zirconia. Of particular interest was the observation of strong scattering anisotropy which can be accounted for by three apparently independent void component morphologies: inter-splat cracks, inter-splat planar pores, and a broad size distribution of fine pores. Such studies, when combined with thermal conductivity 
results, are leading to a better understanding of plasma-sprayed TBCs and thermalsprayed coating in general.

Symposium Support: GM, SNL, Applied Materials, Sulzer-Metco, Praxair Surface Tech., TAFA, and Anval.

\section{Microstructural Characterization Achieved through Electrical Testing (See MRS Proceedings Volume 500)}

Papers presented at Symposium EE on Electrically Based Microstructural Characterization covered a wide variety of material types, applications of electrical testing as a nondestructive way to detect microstructural features at all length scales, and advances in measuring techniques and interpretation. The topics covered included some of the same subjects presented in the earlier MRS meeting in Fall 1995 as well as new contributions. The session on experimental techniques was very exciting as the combination of electrical measurements with STM, AFM, and near-field microscopy were discussed by various presenters. Attendees found the prospect of "seeing" the microstructure as the sample or device is being measured to be very exciting.

Complementary experiments that also hint at the electrical response include luminescence mapping, which was nicely employed to pinpoint the current paths in nonlinear materials such as varistors. Many presenters corroborated their electrical data interpretations with $x$-ray spectra, SEM and TEM micrographs, and computer simulations.

The semiconductors and microelectronic application session discussed the combination of electrical testing with photoelectron studies, and several papers dealt with reactive interfaces in MIS structures and semiconductor heterointerfaces. Several presentations addressed electromigration issues and corrosion of metals deposited on polymers and glasses.

Resistivity measurements were used to detect dislocation formation and mechanical degradation in metals and composites.

The usage of impedance spectroscopy (measurements as a function of frequency) was once again highlighted as an excellent technique for detecting interfacial reactions (intergrain and electrode interfaces) in many material types. Examples were presented of work on magnetic materials, percolating composite systems, ionic conducting materials, and low $k$ and high $-k$ dielectrics. The prospects for electrically based microstructural characterization are very promising.

Sympositm Support: Solartron Instruments, Keithley Instruments, and HP.

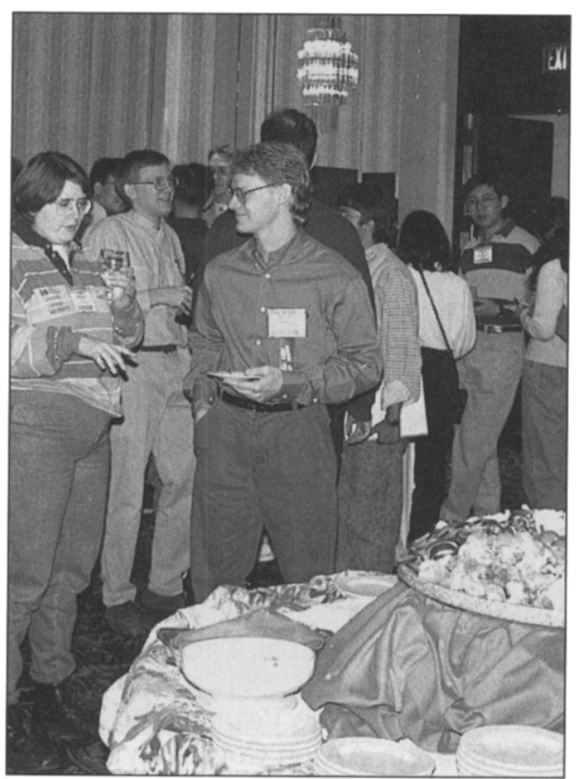

A student mixer (above) was held on Sunday at the 1997 MRS Fall Meeting in Boston. A career workshop and networking session held on Tuesday were well-attended and the job center also attracted several attendees.

\section{Modeling and Processing Highlight FGM Research}

The most well-attended sessions of Symposium GG on Functionally Graded Materials were those dealing with modeling and processing. The modeling session focused primarily on predicting residual stresses and crack tip stress fields, logical extensions of prior work in the field that are important for designing and predicting the performance of graded structures. Some new work on modeling the evolution of graded microstructures was also presented. In the processing sessions, some recently developed fabrication methods were discussed, but general emphasis was placed on improved characterization of the microstructure-property relationships in FGMs produced by the more wellestablished methods. This emphasis was refreshing since, in the past, a general lack of detailed materials characterization work has been performed on materials produced by the various processing methods. FGMs in several new materials systems were discussed along with the related design and performance issues, indicating that new applications for these materials are continuously being investigated. Overall, the FGM field continues to grow at an impressive rate.

Symposium Support: DOE-Office of Basic Energy Sciences and Phillip Morris Research.

\section{Characterization of Materials Structures Utilizes Holographic Techniques}

Electron holography and the related techniques of photoelectron holography and $x$-ray holograpy are developing methods that are finding increasing utilization for characterization of materials structures as well as for performing fundamental physics experiments. Symposium HH on Materials Applications of Electron Holography and Related Techniques highlighted the applications of these techniques for materials analysis. A number of talks concentrated on the use of holographic techniques to characterize field distributions, magnetic material such as nanowires, and the behavior of fluxon vortices in superconductors. In related work, V. Dravid (Northwestern Univ.) discussed the characterization of electrically active interfaces and boundaries in electroceramics, and K. Honda (Fujitsu) showed the use of holography for imaging the potential distribution in ferroelectric thin-film materials such as poly-PZT. M. Lehmann (Dresden Univ. of Tech.) showed how electron holograms could give information on the atomic structure of defects in $\mathrm{ZnTe}$ at resolutions approaching the information limit of the microscope by mathematically compensating for lens aberrations in the reconstructed phase images. Other interesting applications included the determination of morphologies of nanostructured materials such as carbon onions and gold nanoparticles, and the imaging of polymer microstructures by utilizing the phase-sensitivity of the electron wave to create contrast in unstained polymeric materials rather than the more common method of heavy-metal staining. The more newly developed methods of in-line soft x-ray holography, x-ray fluorescence holography, and photoelectron holography were discussed. In-line x-ray holography has now imaged objects with resolutions of ca. $20 \mathrm{~nm}$, with improved imag ing algorithms now under development.

X-ray fluorescence holography can be done in two modes: single energy and inverse multi-energy, with the latter suppressing twin images. Photoelectron holography also can be used in a multienergy mode. These last two methods rely on localized atomic emitters of the reference wave ( $x$-ray or electron, respectively) and have shown themselves able to image the local atomic environments around a particular type of atom in three dimensions and with sub-angstrom resolution.

Symposium Support: JEOL USA, Philips Electron Optics, Hitachi Advanced Research Laboratory, and Gatan. 


\section{NDE Applications of Aging Systems Range from Highways to Nuclear Reactors \\ (See MRS Proceedings Volume 503)}

The current economic incentive to extend the lives of both civilian and military structures points to an increased reliance on NDE to provide accurate data regarding the health of materials in a range of applications. Symposium JJ on Nondestructive Characterization of Materials in Aging Systems brought together researchers developing and applying a wide range of new NDE techniques to the assessment of the condition of materials in many types of aging systems, ranging from highways to aircraft and nuclear reactors. In the first session, R. Green (Johns Hopkins Univ.) gave the plenary talk, describing recent research in laser-generated ultrasound to inspect aerospace structures. The rest of the session dealt with techniques to quantify corrosion damage, radiographic methods, and the electromagnetic characterization of material microstructure.

The second session began with a talk by R. Pethrick (Univ. of Strathclyde), describing a method to gauge the aging of adhesive bonds using dielectric measurements. Other talks dealt with the assessment of the degradation of composite materials. E. Kolesar (Texas Christian Univ.) showed a micro solid-state device that could be used to track the cure of epoxy in resin-matrix composites.

The third session dealt with the characterization of cement in civil structures and was jointly sponsored with Symposium MM on Advances in Materials for Cementitious Composites. This joint session concentrated on methods of assessing the health of cement structures. $\mathrm{K}$. Stokoe (Univ. of Texas-Austin) gave an entertaining talk on monitoring airport pavement using his rolling dynamic deflectometer. Other talks concentrated on various assessing aspects of the health of concrete structural materials.

The fourth session reviewed the current state-of-the-art of the measurement of radiation embrittlement of nuclear reactor pressure vessels. M. Vassilaros (U.S. Nuclear Regulatory Commission) discussed the requirements for techniques to assess radiation embrittlement of steels. This area of research has yet to yield the much needed development that will permit the accurate, real-time tracking of the embrittlement of steels for operational structures. Therefore, very conservative and costly limitations have been placed on many structures.

The fifth session examined the use of NDE techniques to assess damage in such diverse structural materials as concrete, Nylon ropes, ceramic matrix composites, and other turbulent or semi-opaque media. E. Landis (Univ. of Maine) presented a paper on measuring microcrack growth in mortar using CT. His analysis demonstrated the power of using $\mathrm{CT}$ and image analysis software to explain the energy absorbing mechanisms of mortar.

Many NDE techniques were introduced in the sixth session, which was devoted to new and evolving NDE techniques for material characterization. These included such divers technologies as pulsed eddy current crack detection to AFM.

The seventh and last session also dealt principally with MEMS technology that could potentially énable new NDE capabilities. The most exciting development in this regard was the talk by B. Maclean (Sarcos Research Center) on a digital MEMS-based strain gauge for structural health monitoring. This rapidly evolving technology could enable the implementation of true condition-based maintenance with a substantial cost saving to the infrastructure and aviation communities. This talk was followed by one co-authored by B.T. Khuri-Yakub (Stanford Univ.) that demonstrated how a MEMS device could be used to generate and receive ultrasound. Using this device, ultrasound is introduced into the component and received from it without the usual water couplant between the two.

\section{Atomistic Processes of Irradiation- Induced Defects Examined \\ (See MRS Proceedings Volume 504)}

The fundamentals of defects created by the interaction between energetic particle beams and solid materials were studied in Symposium KK on Atomistic Mechanisms in Beam Synthesis and Irradiation of Materials. A range of materials and projectiles was covered, from semiconductors to optical and magnetic materials and from deposition techniques assisted by $100 \mathrm{eV}$ particle to multi-MeV ion beam irradiation.

Both ion implantation and electron irradiation of materials create Frenkel pairs, and these defects may evolve one way or the other. An important difference between the two treatments is that with an electron beam, the number of interstitials exactly equals the number of vacancies, whereas with an ion beam one extra interstitial per ion is always present because the ion itself becomes part of the target. The extra atom has now been observed by comparing a deep level transient spectroscopy characterization of the thermal evolution of ion and electron beam damage in ultrapure silicon ( $\mathrm{S}$. Libertino, Univ. di Catania, Italy).

At very high implantation energies (tens of $\mathrm{MeV}$ ), electronic stopping effects lead to defects and macroscopic deformations, even in semiconductors and metals where normally electronic stopping effects hardly play a role. Modeling of ion tracks in terms of transient thermal processes including melting (M. Toulemonde, CIRIL) can now account for an increasing number of experiments, including the recent observation of the frozen-in distribution of activation energies of flow defects in irradiated silica glass (M. Brongersma, FOM, Netherlands).

Several researchers reported on progress on nanoclusters. A wide variety of elemental and compound crystallites have now been made by ion implantation into a range of host materials. Such structures exhibit promising (nonlinear) optical properties.

Symposium Support: National Electrostatics, High Voltage Engineering Europa, Alabama AEM Univ., and Sumitomo Electric.

\section{Cement-Based Composites Flow into Nontraditional Areas}

The use of traditional cement and the concrete manufactured from it far surpasses the consumption of any other synthetic construction material. Symposium MM on Advances in Materials for Cementitious Composites featured three main topic areas: new applications for cementitious materials, durability and rehabilitation, and the use of waste and by-product materials in cement and concrete. Recent developments in cement processing have made it possible for the use of cement-based composites to expand into new, nontraditional areas (e.g., as mold materials for injection molding of plastics). The use of composite materials (fiber-reinforced polymers) offers the promise of being an advanced technique for the repair of aging, deteriorating structures and in new construction making possible thinner, lighter beams and columns. The utilization of waste and by-product materials in cement and concrete applications continues to an area of intense interest. With increasing emphasis placed on greenhouse emissions, the use of waste materials offers the potential of minimizing the environmental impact of cement production.

Symposium Support: Portland Cement Assn. Federal Highway Adm., NSF, Hanil Cement Manufacturing, and Ssangyong Cement.

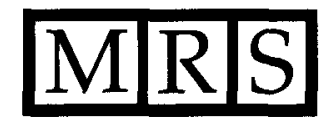

